\title{
Nutritional and Pharmacological Strategies to Regulate Microglial Polarization in Cognitive Aging and Alzheimer's Disease
}

\author{
Emiliano Peña-Altamira *, Sabrina Petralla, Francesca Massenzio, Marco Virgili, \\ Maria L. Bolognesi and Barbara Monti
}

Department of Pharmacy and Biotechnology, University of Bologna, Bologna, Italy

The study of microglia, the immune cells of the brain, has experienced a renaissance after the discovery of microglia polarization. In fact, the concept that activated microglia can shift into the M1 pro-inflammatory or M2 neuroprotective phenotypes, depending on brain microenvironment, has completely changed the understanding of microglia in brain aging and neurodegenerative diseases. Microglia polarization is particularly important in aging since an increased inflammatory status of body compartments, including the brain, has been reported in elderly people. In addition, inflammatory markers, mainly derived from activated microglia, are widely present in neurodegenerative diseases. Microglial inflammatory dysfunction,

OPEN ACCESS

Edited by:

Yu Tang,

University of Texas Southwestern Medical Center, United States

Reviewed by: Björn Spittau, Albert Ludwig University of Freiburg, Germany

Rubem C. A. Guedes, Federal University of Pernambuco,

Brazil

*Correspondence: Emiliano Peña-Altamira luis.penaaltamira3@unibo.it

Received: 07 March 2017 Accepted: 18 May 2017

Published: 07 June 2017

Citation:

Peña-Altamira E, Petralla S, Massenzio F, Virgili M, Bolognesi ML and Monti B (2017) Nutritional and

Pharmacological Strategies to

Regulate Microglial Polarization in Cognitive Aging and Alzheimer's Disease.

Front. Aging Neurosci. 9:175. doi: 10.3389/fnagi.2017.00175 also linked to microglial senescence, has been extensively demonstrated and associated with cognitive impairment in neuropathological conditions related to aging. In fact, microglia polarization is known to influence cognitive function and has therefore become a main player in neurodegenerative diseases leading to dementia. As the life span of human beings increases, so does the prevalence of cognitive dysfunction. Thus, therapeutic strategies aimed to modify microglia polarization are currently being developed. Pharmacological approaches able to shift microglia from M1 pro-inflammatory to M2 neuroprotective phenotype are actually being studied, by acting on many different molecular targets, such as glycogen synthase kinase-3 (GSK3) $\beta$, AMP-activated protein kinase (AMPK), histone deacetylases (HDACs), etc. Furthermore, nutritional approaches can also modify microglia polarization and, consequently, impact cognitive function. Several bioactive compounds normally present in foods, such as polyphenols, can have anti-inflammatory effects on microglia. Both pharmacological and nutritional approaches seem to be promising, but still need further development. Here we review recent data on these approaches and propose that their combination could have a synergistic effect to counteract cognitive aging impairment and Alzheimer's disease (AD) through immunomodulation of microglia polarization, i.e., by driving the shift of activated microglia from the pro-inflammatory $M 1$ to the neuroprotective M2 phenotype.

Keywords: immunomodulation, microglia, cognitive impairment, aging, Alzheimer's disease, drug therapy, bioactive compounds, nutrition 


\section{MICROGLIA AND THEIR POLARIZATION}

Microglia are the resident mononuclear phagocytes of the central nervous system and constitute about $5 \%-20 \%$ of total brain cells displaying regional differences in density (Lawson et al., 1990). These cells are known for their plastic capability and the functional characteristic depending on their activation state; indeed, it is not difficult to find morphological changes these cells undergo depending on their function (Szabo and Gulya, 2013). Under physiological conditions, microglial cells are in a "resting" state of non-activation, and cell morphology is characterized by numerous processes that originate from the soma with distal arborization (Hailer et al., 1996). On the other hand, under conditions of stress, inflammation, injury or upon the effect of certain signals, microglia change their morphology and activation state, from a non-activated to an activated state (Stence et al., 2001). Microglial cells enlarge their cell body and their ramifications become shorter and less arborized. This morphological mutation can induce phagocytic functions and amoeboid ability that allows cells to move toward sites of injury (Tzeng and $\mathrm{Wu}, 1999$ ). A typical feature of this state is the activation of microglia and subsequent release of inflammatory mediators that lead to an increased oxidative and nitrosative stress. This condition promotes the inflammatory process, and persisting microglial activation in this condition shows to be harmful to the nervous tissue (Csuka et al., 2000; Polazzi and Monti, 2010). Activated microglia have two different phenotypes: M1 and M2. Classically activated M1 microglia, activated by LPS or IFN- $\gamma$, have pro-inflammatory, neurotoxic properties, inhibiting the proliferation of lymphocytes; M1 activated macrophages secrete proinflammatory cytokines, such as interleukin IL-1 $\alpha$, IL-1 $\beta$, tumor necrosis factors (TNF) and nitric oxide (NO). Alternatively activated M2 microglia are able to repair small damage, have an anti-inflammatory phenotype, contributing to trophic support of neurons, possess the ability to degrade toxic aggregates and increase the neuroprotective functions thanks to anti-inflammatory interleukin production (Michelucci et al., 2009; Choi et al., 2017). The M2 phenotype is further divided in three subtypes; M2a, M2b, M2c. They may have comparable biochemical functions, but are different in the mechanisms of action. The shift to the M2a subtype is driven by IL-3 and IL- 4 and is involved in collagen formation, tissue repair and immunity against parasites whereas the transition to the M2b subtype is driven by the activation of Toll-like receptor (TLRs) agonists and is able to recruit regulatory T-cells. On the other hand, the M2c phenotype, induced by IL-10, TGF $\beta 1$ and glucocorticoids, is involved in the repair of damage and injury (Chhor et al., 2013; Mecha et al., 2015).

Regarding the beneficial or detrimental role of activated microglia on neuronal survival, the most accredited hypothesis today is that microglia may have a dual role, both neuroprotective and neurotoxic, depending on their activation state, which in turn depends on the nature, length and extension of the insult (Ransohoff and Perry, 2009). In vitro studies in cell cultures have shown the ambivalent role of microglial cells on neurons; neuroprotective, but also neurotoxic, while in vivo studies mainly support the neuroprotective potential of activated microglia (Streit, 2002).

\section{COGNITIVE DEFICITS IN AGING AND AD}

Aging is defined as "the gradual change in an organism that leads to increased risk of weakness, disease and death" (Merriam-Webster thesaurus). It takes place all throughout an organism and the brain is no exception. Aging leads to reduced brain size, neurotransmitter receptor alterations, dendrite loss/regression and electrophysiological changes such as cortical spreading depression alterations, possibly connected also to cortical microglial reactivity, as shown by Iba-1 immunolabeling (Landfield et al., 1978; Earnest et al., 1979; Jacobs et al., 1997; Hof et al., 2002; Duan et al., 2003; Luebke et al., 2004; Batistade-Oliveira et al., 2012; Lima et al., 2014). These alterations lead to what is normally called "age related cognitive decline". Human cognitive function can be classified in basic cognitive functions: attention, working memory, long-term memory, perception; and higher-level cognitive functions: speech and language, decision making, executive control (Glisky, 2007). However, much research on cognitive function has mainly focused on memory, and this could account for variability between aged individuals. The term "mild cognitive impairment" (MCI) was first introduced with the Global Deterioration Scale (Reisberg et al., 1982) for those individuals whose cognitive performance is below normal according to age-matched healthy individuals, especially regarding memory-based performance. The term was further refined in 2004 by the International Working Group on MCI (Winblad et al., 2004), in which affected individuals are considered those that show evidence of cognitive decline after appropriate testing, but maintain normal everyday life activities and functions. MCI appears to be a risk factor for developing dementia as shown by a Chinese study in which about $30 \%$ of patients with MCI developed dementia within 2 years and high plasma C-reactive protein levels were associated with accelerated cognitive decline and increased risk of dementia ( $\mathrm{Xu}$ et al., 2009). Moreover, in another recent study, about $20 \%$ of patients with MCI developed Alzheimer's disease (AD) within 2 years after diagnosis, as assessed through biochemical and magnetic resonance imaging (MRI) performed for brain volumetric assessment, among which hippocampal volume (Nesteruk et al., 2016). AD is a neurodegenerative disease characterized by progressive cognitive decline, present both as familial and sporadic cases. $\mathrm{A} \beta$ production and processing alterations are thought to be one of the causes that trigger the disease. Post-mortem brain studies have shown that $\mathrm{AD}$ pathology hallmarks are the deposition of extracellular $A \beta$ plaques as well as intracellular neurofibrillary tangles (Lantos et al., 1992). Familial AD which accounts for $2 \%$ of all cases and may have a disease onset as early as $40-50$ years, is caused by mutations in the amyloid precursor protein (APP) gene and presenilin 1-2 genes prevalently (Karlinsky et al., 1992; LevyLahad et al., 1995; Sherrington et al., 1995). However, also rare TREM2 receptor mutations increase the risk of developing 
AD (Guerreiro et al., 2013; Jonsson et al., 2013). TREM2 is an innate immune receptor expressed by macrophages and dendritic cells, among other cell types, while in the central nervous system it is expressed mainly by microglia (Hickman and El Khoury, 2014) and is involved in inflammation and phagocytosis. Mutations in TREM2 may impair phagocytosis (Kleinberger et al., 2014), supporting microglial involvement in $\mathrm{AD}$ pathology. On the other hand, sporadic $\mathrm{AD}$ shows late disease onset around 60-70 years for which the apoliprotein E type 4 (APOE- -4$)$ allele has been identified as a major risk factor (Corder et al., 1993). Currently, there is no cure available for $\mathrm{AD}$, yet $\mathrm{AD}$ is responsible for $60 \%-80 \%$ of all dementia cases (Alzheimer's international statistics). Nearly 46.8 million people worldwide were affected by dementia in 2015 and this number is expected to reach 131.5 million cases by 2050 (Alzheimer's international statistics). Thus, dementia represents a burden to society and to healthcare systems.

\section{IMMUNOMODULATION AS A PROMISING THERAPEUTIC STRATEGY TO COUNTERACT COGNITIVE IMPAIRMENT}

Under physiological conditions, immune responses exert positive effects on the brain by regulating neuroplasticity, learning and memory, while injury or chronic stress lead to the increased production of inflammatory molecules such as IL-1, IL-6 and TNF- $\alpha$ which may disrupt neurotrophic factor production/signaling and impair learning and memory (Schneider et al., 1998; Parish et al., 2002; Avital et al., 2003; Balschun et al., 2004; Golan et al., 2004; Soiampornkul et al., 2008). Interestingly, increased pro-inflammatory IL-6 and reduced anti-inflammatory IL-10 levels have been detected in brains from aged mice (Ye and Johnson, 1999, 2001). Moreover, immune status can also influence brain function in humans as the Hoorn Study evidenced that increased levels of inflammatory plasma markers (TNF- $\alpha$, IL-6, IL-8, C-reactive protein) were associated with cognitive decline (Heringa et al., 2014). Because M1 activated microglia produce inflammatory cytokines, and these seem to induce cognitive impairment, immunomodulation strategies aiming to attenuate M1 microglial activation or induce an M1 to M2 microglial shift may contribute to counteract, at least partially, cognitive impairment in aging and in neurodegenerative diseases such as $\mathrm{AD}$. Thus pharmacological and nutritional approaches targeting immunomodulation are currently being developed, and a remarkable amount of data has been produced recently (Figure 1).

\section{PHARMACOLOGICAL APPROACHES TOWARDS IMMUNOMODULATION AND THEIR POTENTIAL APPLICATION IN AGING/AD}

Therapeutic strategies aimed to modify microglia polarization, and therefore leading to immunomodulation, are currently being developed. Pharmacological approaches able to shift microglia from the M1 pro-inflammatory to the M2 neuroprotective phenotype could become new therapeutic tools in neurodegenerative diseases such as $\mathrm{AD}$ and also in normal brain aging. In the following sections we discuss on potentially interesting and successful immunomodulatory targets including glycogen synthase kinase-3 (GSK3) $\beta$, b-site APP-cleaving enzymes (BACEs), Janus kinase (JNK), phosphodiesterases (PDEs), AMP-activated protein kinase (AMPK), histone deacetylases (HDACs) and peroxisome proliferator-activated receptor gamma (PPAR- $\gamma$ ) according to currently available evidence.

\section{GSK-3 $\beta$}

GSK-3 $\beta$ is a serine/threonine kinase, involved in several signaling pathways such as cell proliferation and inflammation (Cui et al., 1998; Park et al., 2006). Notably, GSK-3 $\beta$ appears to be responsible for tau hyperphosphorylation (Sperber et al., 1995), detaching tau from microtubules and inducing tau precipitation as intracellular neurofibrillary tangles (NFTs; Ferrer et al., 2002), a hallmark of AD. Moreover, GSK-3 $\beta$ has been shown to mediate the release of inflammatory cytokines in LPS-activated microglia in vitro (Green and Nolan, 2012), thus GSK-3 could be a promising target. Tideglusib (NP031112), a thiadiazolidinine derivative, prevents inflammation and neurodegeneration in a kainic-acid inflammation rat model (Luna-Medina et al., 2007) and has reached phase II clinical trials on AD patients (Clincaltrials.gov identifier NCT00948259), appearing safe though not effective enough (del Ser et al., 2013; Lovestone et al., 2015). In another study, two triazolopyridine derivative GSK-3 inhibitors (C-7a and C-7b) reduced $A \beta$ neurotoxicity and tau hyperphosphorylation in vitro and improved cognitive deficits in a transgenic $\mathrm{AD}$ mouse model (Noh et al., 2013), though no anti-inflammatory effects were investigated. More recently, triazinones displayed in vitro antiGSK-3 and anti-BACE-1 activity plus neuroprotective and neurogenic effects besides good brain permeability in vivo (Prati et al., 2015), however no anti-inflammatory data are currently available. Lastly, L807mts, a highly selective GSK-3 peptide derivative inhibitor, reduced $A \beta$ levels, reduced inflammation and enhanced autophagy in a transgenic $\mathrm{AD}$ mouse model (Licht-Murava et al., 2016).

\section{BACEs}

$A \beta$ aggregates are generated by the cleavage of the membraneassociated APP by $\alpha, \beta$ and $\gamma$-secretases. Through two successive proteolytic cleavages by $\alpha$-secretase and $\gamma$-secretase, a harmless peptide, p3, is produced. On the other hand, $\beta$-secretase operates a different cleavage leading to the production of two neurotoxic peptides of 40 and 42 amino acids each, called $A \beta 40$ and $A \beta 42$, respectively. The first $\beta$-secretase identified was BACE-1, a type I transmembrane aspartic protease (Vassar et al., 1999). Because $A \beta$ can induce neuroinflammation, BACE-1 inhibitors can contribute indirectly to inhibiting microglial M1 activation and research on their potential application is ongoing. In vivo treatment with the aminoisoindole AZ-4217, a BACE-1 inhibitor, resulted in long term reduced $\mathrm{A} \beta$ deposition 


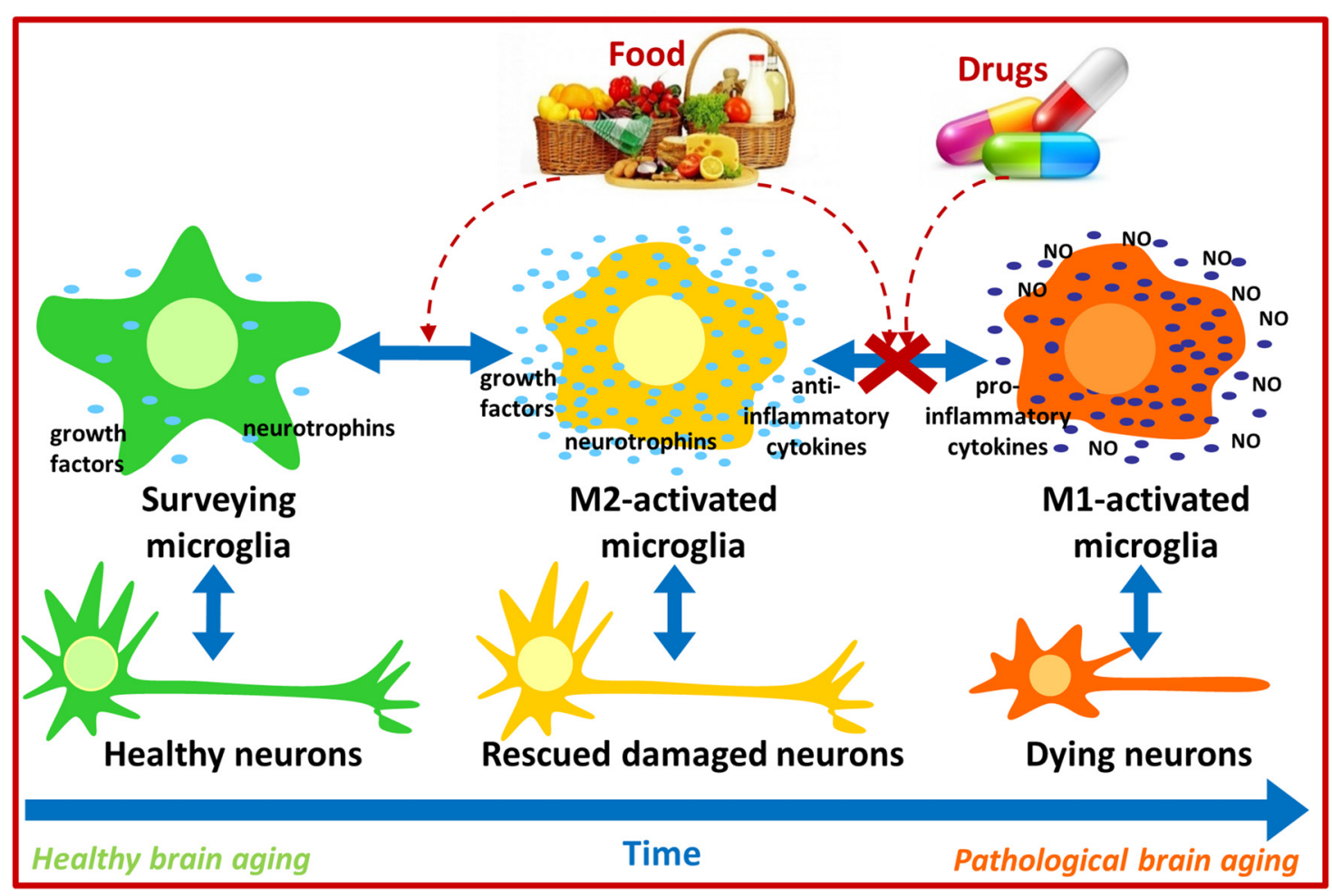

FIGURE 1 | Possible pharmacological and nutritional approaches towards immunomodulation to counteract pathological brain aging. Food bioactive compounds and/or synthetic compounds may influence microglial activation state contributing to neuronal survival and thus improve cognitive function during aging.

in an APP transgenic cerebral amyloidosis mouse model (Eketjäll et al., 2013). In another study, treatment with the BACE inhibitor RO5508887 reduced amyloid plaque load and formation in an $\mathrm{AD}$ transgenic mouse model and combined treatment with an anti-A $\beta$ antibody (gantenerumab) further enhanced these effects (Jacobsen et al., 2014), however the impact on cognition was not investigated. Also, as previously stated, triazinones displayed anti-GSK-3 and anti-BACE-1 activity (Prati et al., 2015) while NB-360, another BACE-1 inhibitor was able to block $A \beta$ deposition and the accumulation of inflammatory cells in a transgenic $\mathrm{AD}$ mouse model (Neumann et al., 2015). Noteworthy, a clinical trial to study the effect of the BACE-1 inhibitor LY3202626 on patients with mild AD dementia, as of February 2017 was recruiting patients (Clinicaltrials.gov identifier NCT027 91191).

\section{JNK}

Mitogen-activated protein kinases (MAPKs) are serine-threonine kinases that mediate intracellular signaling. JNK is a major cellular stress response protein induced by oxidative stress and its activation is believed to be an early event in $\mathrm{AD}$ (Zhu et al., 2001). Among the MAPKs, JNK is one of the essential mediators of microglial proinflammatory functions (Waetzig et al., 2005), it is a component of signaling pathways that lead to inflammation, and it can control the synthesis and release of proinflammatory molecules by LPS-activated microglia (Hidding et al., 2002). Moreover, the JNK-AP1 signaling pathway mediates the increased expression of inflammatory genes induced by $\mathrm{A} \beta$ peptides in human brain endothelial cells and in AD brain (Vukic et al., 2009). Thus JNK is an attractive target for $\mathrm{AD}$ prevention/therapy. In one study, treatment of LPS-activated primary rat microglia with conserved dopamine neurotrophic factor (CDNF) resulted in reduced production of inflammatory cytokines by suppressing the phosphorylation of JNK and thus inhibiting JNK signaling (Zhao et al., 2014). Therefore, CDNF use in vivo seems promising. Another recent in vivo study showed that administration of the JNK inhibitor SP600125 resulted in cognitive deficit improvement in a transgenic $\mathrm{AD}$ mouse model by reducing $\mathrm{A} \beta$ production, inflammatory responses and synaptic loss (Zhou et al., 2015). Interestingly, in vivo administration of the small molecule LX2343 improved cognitive deficits in a transgenic AD mouse model by inhibiting both JNK and BACE-1 activity, reducing $A \beta$ production and promoting autophagy (Guo et al., 2016), though no direct anti-inflammatory mechanisms were investigated.

\section{PDEs}

PDEs act as regulators of intracellular signaling cascades through the control of 2 second messengers, cyclic adenosine monophosphate and cyclic guanosine monophosphate. Recent 
findings point to PDE inhibitors as compounds able to affect different mechanisms underlying $\mathrm{AD}$, as shown by active ongoing research with these molecules. Administration of sildenafil, a PDE-5 inhibitor, improved cognitive deficits, reduced $\mathrm{A} \beta$ levels and neuroinflammation in a transgenic $\mathrm{AD}$ mouse model (Zhang et al., 2013). Moreover, administration of another PDE-5 inhibitor, yonkenafil, resulted in improved cognitive function, increased neurogenesis in the dentate gyrus and reduced activation of microglia and astrocytes in a transgenic AD mouse model (Zhu et al., 2015), therefore showing also anti-inflammatory effects. In another study, the PDE-7 inhibitor S14 improved cognitive impairment, reduced $\mathrm{A} \beta$ deposition and tau phosphorylation in a transgenic $\mathrm{AD}$ mouse model (Perez-Gonzalez et al., 2013). Also in an in vitro study, the $\mathrm{PDE}-3$ inhibitor cilostazol reduced $\mathrm{A} \beta$ production by increasing ADAM10 expression (Lee et al., 2014), though no anti-inflammatory effects were investigated. Noteworthy, a phase IV clinical trial to examine the additive effects of cilostazol on donepezil-treated mild to moderate $\mathrm{AD}$ patients has been completed (Clinicaltrials.gov identifier NCT01409564) and in a very recent small clinical trial, cilostazol administration as an add-on therapy reduced cognitive decline in AD patients (Tai et al., 2017). In another study, administration of GEBR-7b, a PDE-4D inhibitor, improved cognitive deficits in a transgenic AD mouse model (Sierksma et al., 2014) though the underlying mechanisms of action remain to be discovered. Lastly, in a very recent in vivo study, administration of the PDE-4 inhibitor FFM reversed cognitive deficits in a transgenic $\mathrm{AD}$ mouse model by increasing CREB phosphorylation and BDNF levels and reducing inducible NO synthase (iNOS), TNF- $\alpha$ and IL-1 $\beta$ levels (Guo et al., 2017).

\section{AMPK}

AMPK is a highly conserved energy sensor involved in mitochondrial biogenesis, cellular stress responses and regulation of inflammation (Corton et al., 1994; Zong et al., 2002; Giri et al., 2004). Because overactivated AMPK has been reported to accumulate in neurons containing tangles in $\mathrm{AD}$ brains (Vingtdeux et al., 2011) and AMPK can phosphorylate tau protein (Domise et al., 2016), AMPK may represent an interesting target, though its role in $\mathrm{AD}$ is not fully understood. While inhibition of AMPK with the compound C (CC) improved hippocampal synaptic plasticity impairment induced by $\mathrm{A} \beta$ in a transgenic $\mathrm{AD}$ mouse model (Ma et al., 2014) AMPK activators have also shown beneficial effects in $\mathrm{AD}$ models. An example are the anti-epileptic drugs topiramate and levetiracetam which improved cognitive deficits, reduced $A \beta$ production, increased the activation of AMPK and inhibited HDAC activity in a transgenic AD mouse model (Shi et al., 2013). Moreover, a phase II levetiracetam clinical trial on MCI patients was completed in 2012, though no results were posted (Clinicaltrials.gov identifier NCT01044758). Also, while not tested in $\mathrm{AD}$, telmisartan, an angiotensin II type 1 receptor blocker, increased brain AMPK activation and microglial M2 gene expression in an LPS-induced neuroinflammation mouse model (Xu et al., 2015) thus its application in $\mathrm{AD}$ may deserve attention. In another study, administration of the AMPK activator AICAR, improved cognitive deficits in a streptozotocin-induced $\mathrm{AD}$ rat model (Du et al., 2015) by restoring mitochondrial functions, though no anti-inflammatory effects were investigated. Lastly, treatment with the small molecule THSG exerted anti-inflammatory effects on LPS-activated microglia by reducing iNOS, COX-2, TNF$\alpha$ and IL-6 levels and increased AMPK phosphorylation levels, thus confirming AMPK activation (Park et al., 2016).

\section{HDACs}

The effects of histone acetylation on the activation of gene expression were unknown until the 1960s (Allfrey et al., 1964). Acetylation reduces the positive charge of basic histone proteins thus decreasing their interaction with DNA and allowing gene expression. More in detail, this process is finely regulated by several Histone Acetyl Transferases (HATs) and HDACs. Recently, the effects of HDAC inhibitors on immunomodulation have increasingly generated interest due to a potential role in immunotherapy. In fact, class I HDAC inhibitors have been reported to increase transcription of neuronal genes, provide neuroprotective effects, and enhance cognitive abilities. Moreover, class I HDAC inhibitors such as valproic acid (VPA), trichostatin A (TSA), suberoylanilide hydroxamic acid (SAHA), sodium phenylbutyrate (SB) and MS-275 have been shown to enhance neurite outgrowth, synaptic plasticity, neurogenesis, neuronal differentiation and axon regeneration in cultured neurons and in vivo (Laeng et al., 2004; Siebzehnrubl et al., 2007; Koriyama et al., 2014). In one in vivo study, administration of the HDAC inhibitor SB, prevented cognitive deficits and reduced $A \beta$ and GFAP levels, suggesting an anti-inflammatory effect in a transgenic AD mouse model (Ricobaraza et al., 2011). Another in vivo study showed that treatment with the benzamide HDAC inhibitor MS-275 improved cognitive deficits and reduced microglial activation and $A \beta$ accumulation in a transgenic AD mouse model (Zhang and Schluesener, 2013). Lastly, in another in vivo study, SAHA treatment restored H3 acetylation and BDNF levels (Sharma and Taliyan, 2016) in mice fed a fat-enriched diet which developed insulin resistanceinduced cognitive decline. While not being an $\mathrm{AD}$ study, insulin resistance is considered a risk factor for $\mathrm{AD}$ (Fava et al., 2017) and thus SAHA may deserve attention in $\mathrm{AD}$ research.

\section{PPAR- $\gamma$}

PPAR- $\gamma$ is a nuclear receptor that, after binding peroxisome proliferators, binds to specific DNA PPAR response elements regulating the expression of genes involved in fatty acid peroxisomal beta-oxidation (Dreyer et al., 1993). Current evidence shows that PPAR- $\gamma$ activation may prove useful in $\mathrm{AD}$ therapy. In one in vitro study pioglitazone, a PPAR- $\gamma$ agonist, inhibited iNOS and the production of IL- $1 \beta$, TNF- $\alpha$ and IL-6 in LPS-activated HAPI microglia (Ji et al., 2010). Unfortunately, a phase II pioglitazone clinical trial performed in mild to moderate $\mathrm{AD}$ patients completed in 2009 produced no results (Clinicaltrials.gov identifier 
NCT00982202). In another in vitro study, the small molecule SNU-BP inhibited inflammatory cytokine production and iNOS in LPS-stimulated microglia by activating PPAR- $\gamma$. SNU-BP also increased IL-4 and arginase-1 expression, considered as M2 microglial phenotype markers (Song et al., 2016), thus SNU-BP may deserve in vivo testing as well. Interestingly, PPAR- $\gamma$ agonists able to act on other targets are also being studied in AD therapy. Such is the case for T3D-959, a PPAR- $\gamma$ and PPAR- $\delta$ agonist that reversed neurodegeneration in a streptozotocin-induced $\mathrm{AD}$ mouse model though no anti-inflammatory mechanisms were investigated (Tong et al., 2016). Noteworthy, a phase II clinical trial focused on TD3D-959 in mild to moderate AD patients as of June 2016 was being performed (Clinicaltrials.gov identifier NCT02560753). Lastly, MH84 a PPAR- $\gamma$ agonist $/ \gamma$ secretase modulator, reduced A $\beta 42$ in HEK293APPwt cells, characterized by elevated $\mathrm{A} \beta 42$ levels, and improved mitochondrial dysfunction (Pohland et al., 2016), thus performing in vivo MH84 studies applied to AD therapy may be worth.

\section{NUTRITIONAL APPROACHES TOWARDS IMMUNOMODULATION AND THEIR POTENTIAL APPLICATION IN AGING/AD}

Interest in the role of diet in health developed after several epidemiological studies found an association between the Mediterranean diet and a lower risk of developing cardiovascular diseases and death (Menotti et al., 1996; Knoops et al., 2004). Nutritional approaches to target immunomodulation could become interesting strategies given that foods we consume on a daily basis, especially plant-based foods (widely present in the Mediterranean diet), besides providing nutrients contain also non-essential molecules, termed bioactive food compounds, able to exert multiple effects throughout the body by acting on different targets. Science has started understanding the effect of these molecules, and they could join the list of key players in immunomodulation strategies.

Bioactive compounds comprise a heterogeneous group of thousands of molecules. They can be classified into four/five major groups depending on authors: carotenoids (including carotenes and xantohpylls); phytosterols (including sterols and stanols); phenolic compounds (including chlorogenic acid); polyphenols (including flavonoids, stilbenes, lignans and curcuminoids) and sulfur compounds (including glucosinolates; Lozano et al., 2016).

Being a heterogeneous group of molecules with distinct chemical structures, bioactive compounds exert therefore different effects such as anti-inflammatory, antioxidant, hypoglycemic, cholesterol-lowering, estrogen mimicking, immunostimulant, neurogenic and neuroprotective effects.

Nutritional strategies based on the use of bioactive compounds can include dietary enrichment, by increasing the intake of foods containing naturally high amounts of bioactive compounds; intake of bioactive compound-enriched supplements, such as concentrated extracts or purified single molecules; intake of foods fortified with bioactive compounds. On the other hand, dietary supplements containing high amounts of bioactive compounds are already commercially available.

Given their multifaceted properties, many studies have focused on the effect of bioactive compounds which we summarize in the following sections and discuss on their potential use in aging/AD.

\section{Carotenoids}

Well-known carotenoids such as $\beta$-carotene, lycopene and lutein can be found in carrots, tomatoes, peaches and peppers among other foods (Lozano et al., 2016). Lycopene, highly concentrated in tomatoes, was able to reduce BV-2 microglial cell activation after LPS treatment in vitro by reducing COX-2 expression (Lin et al., 2014). Moreover, lycopene exerted anti-inflammatory effects and enhanced cognitive performance in a $A \beta 42$-induced $\mathrm{AD}$ rat model by downregulating inflammatory cytokines such as TNF- $\alpha$ and IL1-B (Sachdeva and Chopra, 2015). Also lutein, highly present in parsley, was able to reduce LPS-induced neuroinflammation in BV-2 microglial cells, by significantly inhibiting iNOS and cyclooxygenase- 2 activity, as well as by reducing TNF- $\alpha$ and IL- $1 \beta$ production (Wu et al., 2015). However, no in vivo data on the anti-inflammatory effect of lutein are currently available. Interestingly, a human study involving nearly 7000 participants aged 50 or older found an association between high levels of serum lycopene and lutein and a lower risk of mortality by $\mathrm{AD}$ (Min and Min, 2014). Current research on $\mathrm{AD}$ and bioactive compounds has also focused on less-known carotenoinds. For example, fucoxanthin, a carotenoid abundant in brown seaweeds, exerted anti-inflammatory effects and reduced reactive oxygen species levels in A $\beta 42$ treated BV2 microglial cells (Pangestuti et al., 2013). Moreover, in another in vitro inflammationinduced microglial cell culture study, fucoxanthin was able to inhibit the secretion of inflammatory cytokines after LPS treatment (Zhao et al., 2017). However, no in vivo data on the anti-inflammatory effect of fucoxanthin are currently available.

On the other hand, carotenoids contained in saffron, such as crocin and crocetin, exerted in vitro anti-inflammatory effects on LPS-treated rat brain microglial cells by inhibiting NO synthesis from iNOS and the production of inflammatory cytokines (Nam et al., 2010). Also, in another study, trans-crocetin was able to improve $A \beta$ degradation in monocytes derived from $A D$ patients (Tiribuzi et al., 2017) thus it would be interesting to determine whether trans-crocetin may induce the same effect in microglia. Remarkably, crocin intraperitoneal administration showed neuroprotective effects in vivo, by blocking $A \beta$-induced apoptosis in an AD animal model (Asadi et al., 2015) which means crocin is able to cross the blood brain barrier, despite its hydrophilic nature.

\section{Phytosterols}

Phytosterols such as $\beta$-sitosterol, stigmasterol and campesterol can be found in vegetable oils, such as olive oil, cereals, legumes and nuts (Lozano et al., 2016). While a direct 
anti-inflammatory activity in $\mathrm{AD}$ has not been reported for most phytosterols, their anti-inflammatory effects may not have been thoroughly investigated. Stigmasterol, one of the most prevalent phytosterols in foods, exhibited beneficial effects in vivo in an $\mathrm{AD}$ animal model, mainly by reducing $\mathrm{A} \beta$ generation (Burg et al., 2013). In another in vivo study, a plant sterol-enriched diet was able to prevent cognitive impairment in SAMP8 mice, a non-transgenic AD animal model. This beneficial effect could derive from the fact that plant sterols may substitute lost cholesterol in SAMP8 mice brains (Pérez-Cañamás et al., 2016). AD studies have also focused on less common phytosterols. For example, spinasterol, isolated from Aster scaber, widely used in Korean cuisine, exerted anti-inflammatory effects on LPS-activated BV-2 microglial cells by upregulating hemeoxygenase- 1 and reducing the production of TNF- $\alpha$, IL-1 $\beta$ and PGE2 (Jeong et al., 2010). However, no anti-inflammatory effects for spinasterol in aging/AD models have been reported. Moreover, fucosterol, a phytosterol contained in brown seaweed, exerted anti-inflammatory effects on RAW264.7 macrophages by inhibiting the production of $\mathrm{NO}$ and the expression of iNOS and cyclooxygenase-2 (Jung et al., 2013). This suggests that fucosterol may exert the same anti-inflammatory effects on microglial cells. Interestingly, a recent in vitro study additionally shows that fucosterol may also exert BACE-1 inhibitory effects (Jung et al., 2016).

\section{Phenolic Compounds/Polyphenols}

Phenolic compounds such as tyrosol, capsaicin, coumaric, caffeic and chlorogenic acid can be found in citrus, olives, oats and soybeans wheras polyphenols, the most heterogeneous group of bioactive compounds, which includes quercetin, rutin, flavan3-ols, catechins, anthocyanins, flavones (luteolin), isoflavones (phytoestrogens such as genistein, daidzein), curcumin and lignans can be found in onions, blueberries, red wine and tea (Lozano et al., 2016). Chemically speaking, phenolic acids belong to the supercategory of polyphenols, and thus we describe several examples together. In one in vitro study, caffeic acid, naturally present in honeybee propolis, exerted anti-inflammatory effects on BV-2 microglia by inhibiting the expression of iNOS and cyclooxygenase-2 (Tsai et al., 2015). Moreover, caffeic acid oral administration improved cognitive deficits in an A $\beta 25-35$-induced AD animal model, possibly by inhibiting lipid peroxidation and NO production (Kim et al., 2015).

In another study, artoindonesianin $\mathrm{O}$, a phenolic compound found in mulberries, blocked $A \beta-42$ toxicity in an in vitro model of AD (Qiao et al., 2015). While no in vivo anti-inflammatory properties for artoindonesianin $\mathrm{O}$ have been reported, a recent report showed that artoindonesianin $\mathrm{O}$ is a potent lipooxygenase inhibitor, thus it could also play an anti-inflammatory role in vivo (Lang et al., 2016).

On the other hand, carnosic acid found in rosemary and sage, was able to inhibit LPS-induced activation of MG6 microglial cells in vitro, by reducing iNOS levels (Yanagitai et al., 2012). Moreover, carnosic acid was able to improve cognitive deficits in an Aß40-induced AD rat model (Rasoolijazi et al., 2013).
In another study, oral administration of ferulic acid, found in seeds and cereals, particularly flaxseed (Beejmohun et al., 2007), inhibited microglial activation in an $\mathrm{A} \beta 42$-induced $\mathrm{AD}$ mouse model by decreasing IFN-gamma levels in the hippocampus (Kim et al., 2004). Moreover, ferulic acid administration was able to improve cognitive deficits in a transgenic $\mathrm{AD}$ mouse model (Mori et al., 2013).

Interest in the application of other polyphenols normally present in foods for $\mathrm{AD}$ research has constantly increased. In fact, oral administration of oleuropein aglycone, found in olive leaves, significantly attenuated astrocyte and microglial activation in an $\mathrm{A} \beta 42$-induced $\mathrm{AD}$ rat model (Luccarini et al., 2014). Moreover, oleuropein aglycone oral administration also improved cognitive deficits and reduced $A \beta 42$ plaque area and number in a transgenic AD mouse model (Pantano et al., 2017). Also resveratrol, a polyphenol found in red grapes and wine, was able to inhibit $A \beta$-induced activation of $B V-2$ microglial cells by reducing the production of inflammatory factors such as TNF- $\alpha$, IL- $1 \beta$ and NO (Yao et al., 2015). Moreover, resveratrol administration showed anti-inflammatory and anti-apoptotic effects in vivo in an $\mathrm{A} \beta 42$-induced $\mathrm{AD}$ mouse model by inhibiting PDE-4 signaling (Wang et al., 2016). Interestingly, dietary resveratrol also extended life span of SAMP8 mice, a non-transgenic $\mathrm{AD}$ mouse model through sirtuin activation (Porquet et al., 2013). However, a resveratrol phase II clinical trial on patients with mild to moderate $\mathrm{AD}$, resulted in no benefit to patients (Turner et al., 2015; Clinicaltrials.gov identifier NCT01504854).

In another study, curcumin, mainly found in turmeric, inhibited $A \beta$ induced microglial activation in vitro (Shi et al., 2015). Moreover, curcumin administration improved cognitive deficits in an $\mathrm{AD}$ transgenic rat model, possibly through an anti-inflammatory effect by activating PPAR-gamma (Liu et al., 2016) and a phase II curcumin clinical trial on mild to moderate AD patients was concluded in 2009 though no results were posted (Clinicaltrials.gov identifier NCT00099710).

Regarding phytoestrogens, genistein, the main isoflavone found in soy, exerted anti-inflammatory effects on LPS-activated BV-2 microglia by blocking TLR4 signaling (Jeong et al., 2014). Moreover, genistein improved cognitive deficits in an $\mathrm{AD}$ mouse model (Bonet-Costa et al., 2016). However, oral administration of soy isoflavones $(100 \mathrm{mg} /$ day) to $\mathrm{AD}$ patients for 6 months resulted in no cognitive deficit improvement (Gleason et al., 2015; Clinicaltrials.org identifier NCT00205179). This could be due to the fact that genistein is metabolized by the gut microbiome to its most active metabolite, equol, only in presence of specific bacteria in the gut microbiome such as Slackia isoflavoniconvertens (Matthies et al., 2009).

In another study, anthocyanin in vitro treatment inhibited LPS-induced BV-2 microglial activation by reducing IL-1 $\beta$ levels (Meireles et al., 2016). Moreover, a diet supplemented with $1 \%$ anthocyanin extracts was able to prevent cognitive deficits in a transgenic AD mouse model (Yamakawa et al., 2016) whereas pomegranate polyphenol administration exerted anti-inflammatory effects on a transgenic AD mouse model by reducing TNF- $\alpha$ brain levels and microgliosis (Rojanathammanee et al., 2013). 
Even the polyphenol epigallocatechin from green tea, attenuated $\mathrm{A} \beta$ EOC 13.31 microglial activation in vitro (ChengChung Wei et al., 2016). While no in vivo anti-inflammatory effects for green tea catechins in $\mathrm{AD}$ have been reported, green tea epicatechin administration combined with treadmill exercise improved cognitive deficits in an $\mathrm{AD}$ transgenic mouse model (Zhang et al., 2016). Also, a phase II epigallocatechin clinical trial on early stage AD patients was completed on 2016 though no results have been published yet (Clinicaltrials.gov identifier NCT00951834).

Lastly, rutin, a citrus flavonoid, exerted anti-inflammatory and antioxidant effects in an $\mathrm{AD}$ transgenic mouse model, improving spatial memory (Xu et al., 2014).

Interestingly, one in vivo study showed that dietary polyphenols may exert in part their beneficial effects after being converted into phenolic acids by intestinal microbiota (Wang et al., 2015).

\section{Sulfur Compounds}

Sulfur compounds such as glucosinolates (isothiocyanate, sulphoraphane) and Allium genus compounds (allin, allicin and ajoene) can be found in cabbage, broccoli, onions and garlic (Lozano et al., 2016). Sulforaphane, an isothiocyanate derived from glucoraphanin hydrolysis in broccoli, exerted anti-inflammatory effects in vitro on LPS-activated microglia by decreasing IL- $1 \beta$, IL- 6 and TNF- $\alpha$ expression (Brandenburg et al., 2010). Moreover, sulforaphane was able to extert anti-inflammatory effects against $\mathrm{A} \beta 42$-induced microglial activation in THP-1 macrophages through STAT-1 dephosphorylation and the activation of heme-oxygenase 1 (An et al., 2016). While no in vivo anti-inflammatory effects in $\mathrm{AD}$ disease have been reported for sulforaphane, sulforaphane administration exerted neuroprotective effects in an $\mathrm{AD}$ aluminum-induced mouse model (Zhang et al., 2015). Moreover, a very recent study showed that treatment with moringin, an isothiocyanate derived from the edible plant Moringa oleifera, exerted potent in vitro ant-inflammatory effects on LPS-activated RAW 264.7 macrophages (Giacoppo et al., 2017). Also, moringin showed in vivo anti-inflammatory effects in a Parkinson's disease mouse model (Giacoppo et al., 2017) and thus it would be worth testing moringin also on aging and $\mathrm{AD}$ models.

\section{IN VITRO AND IN VIVO CONSIDERATIONS}

Microglial cells are able to exert neuroprotective effects towards neurons challenged with toxic insults. Evidence shows that this mechanism can be exerted either through direct contact or through factors secreted by microglia, as shown by in vitro studies (Polazzi et al., 2001, 2009, 2013). On the other hand, nanomolar concentrations of $A \beta$ induced neuronal death in mixed neuronglial cerebellum cultures, possibly through a microglia mediated mechanism (Neniskyte et al., 2011), thus outlining a multifaceted role of microglial activation. Of remarkable importance are the limitations of the in vitro and in vivo studies here discussed. Regarding both pharmacological and nutritional in vitro studies, the abovementioned molecules may actually be metabolized by the liver cytochrome P450 systems and thus their properties may change, thus further research in in vivo models to understand the effect of liver metabolism will be required. Moreover, regarding nutritional in vitro studies, the bioactive compounds here cited may not all cross the blood brain barrier and thus may not reach the identified targets. Also, dietary bioactive compounds may be transformed by the gut microbiome, as is the case for genistein which is converted into equol, its most active derivative (Matthies et al., 2009). This means further research needs to be performed in order to understand whether food bioactive compounds used in in vitro studies are actually the same identical molecules crossing the blood brain barrier after being absorbed in the gastrointestinal tract. Also, most nutritional based studies have focused on the administration of a single bioactive compound. Bioactive compound mixtures, as present in foods, could modify/enhance their activity mutually. For example, as stated in the previous sections, brown seaweeds contain both the carotenoid fucoxanthin and the phytosterol fucosterol and thus may exert a synergistic effect on $\mathrm{AD}$ when brown seaweeds are consumed with the diet. However, one caveat of the above described nutritional approaches is that single compounds may have been used at concentrations much higher than those present in foods and thus the observed effects may not be attainable through food intake. In fact, in the previously described in vivo lycopene $\mathrm{AD}$ study (Sachdeva and Chopra, 2015), lycopene was used at concentrations reaching $4 \mathrm{mg} / \mathrm{kg}$ of body weight. In order to reach such dietary intake in humans, more than $2 \mathrm{~kg}$ of fresh tomatoes would need to be consumed (Kamiloglu et al., 2014). However, dietary bioactive compound supplementation may overcome this problem. Also, regarding nutritional approaches, intestinal absorption should not be underestimated as is the case for some carotenoids, which are partially absorbed at the intestinal level, as is the case for lycopene, which shows about 20\% absorption levels (Moran et al., 2015) and thus, circulating blood carotenoid levels may be too low compared to those used in the previously described studies. Moreover, carotenoid polarity influences greatly their absorption, though dietary fat intake and food matrix also influence carotenoid intestinal absorption, as shown in an in vitro Caco-2 intestinal barrier model (Mashurabad et al., 2017). However, carotenoid absorption problems may also be overcome by avoiding oral carotenoid administration, for example, through intraperitoneal administration, as previously stated for crocin in vivo studies (Asadi et al., 2015). On the other hand, AD animal studies pose several limitations when compared to human studies, being species-specific differences the most important ones. While extremely useful, currently available transgenic AD models are based on the overexpression of one or more proteins, as suggested from familial $\mathrm{AD}$ genetic causes, involved in $\mathrm{AD}$ pathology in order for animals to develop AD. However, protein overexpression at much higher than physiological levels, such as APP transgenic mice which develop cerebral amyloidosis (Jacobsen et al., 2014; Neumann et al., 2015) may lead to negative results after compound administration perhaps not necessarily due to compound inefficacy but rather to forced protein expression levels much higher than in $\mathrm{AD}$ patients. At 
such high transgene expression levels, the studied molecules may not be able to exert detectable beneficial effects, while they could do so at physiological protein expression levels. Another issue regards compound metabolism since pharmacological and food bioactive compounds may be differently metabolized by rodents, the most widely used animal model for $\mathrm{AD}$ research. Moreover, gut microbiome differences present in humans which can influence bioactive compound metabolism, may not be as sharp in rodents and rodent intestinal permeability may differ from human intestinal permeability for the above mentioned pharmacological and food bioactive compounds. Noteworthy, the amount of pharmacological or food bioactive compounds used in animal studies, when extrapolated to human studies may be quite high. This suggests further consideration is needed when designing human studies. Despite these limitations, animal models continue to be an invaluable resource in $\mathrm{AD}$ research. Furthermore, regarding pharmacological approaches in human studies, compound delivery conditions may not be optimal: orally administered compounds may need to be increasingly stable and/or rendered more permeable to brain parenchyma in order to reach their targets in affected areas. Accordingly, pharmacological compound delivery methodologies should be further developed. One last consideration regarding human studies is that gut microbiome differences between different world populations may account for different outcomes in clinical trials when dealing with food bioactive compounds, in case these are metabolized by gut microbiota. Such is the case for genistein conversion into equol, its most active derivative, given that only about $30 \%-50 \%$ of the world population contains gut bacteria able to perform this specific chemical reaction (Atkinson et al., 2005).

\section{CONCLUSION}

Pharmacological and nutritional strategies aimed at modulating microglial activation (Figure 2) offer much potential for future

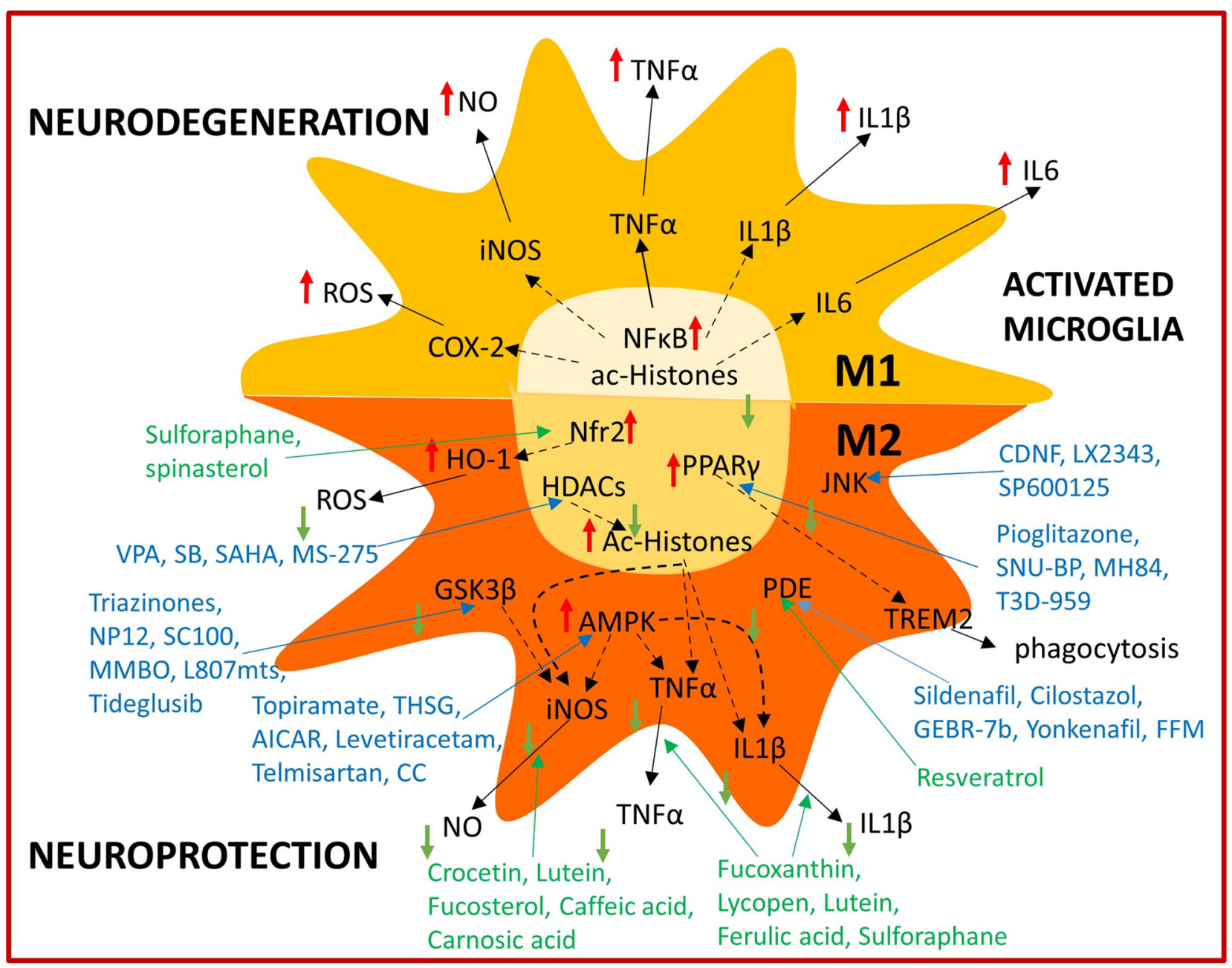

FIGURE 2 | Summary of immunomodulatory bioactive and synthetic compounds. Bioactive (green) and synthetic (blue) compounds are able to modulate microglial activation by shifting from the M1 neurotoxic to the M2 neuroprotective phenotype acting on several intracellular targets. 
brain aging and $\mathrm{AD}$ therapy. However, they also represent a big challenge and further research is needed to understand their potential application in humans. Clinical trials focused on immunomodulation targets performed so far, have not resulted in $\mathrm{AD}$ patient improvement, however it has to be considered that immunomodulatory strategies may have preventive rather than protective effects. This could derive from the fact that initial $\mathrm{AD}$ pathology hallmarks such as $\mathrm{A} \beta$ accumulation may start years before symptoms manifest. In fact, protein tangles may already be present in early life and even in healthy aged people (Braak and Del Tredici, 2011), thus perhaps only when a combination of biochemical $(\mathrm{A} \beta$ deposition) and cellular factors ( $\mathrm{A} \beta$ clearance dysfunction) are present, may $\mathrm{AD}$ pathology progress. A considerable amount of $A \beta$ turnover is handled by the glymphatic system in the brain and perivascular circulation and dysfunction in these systems may contribute to $A \beta$ accumulation as well (TarasoffConway et al., 2015). Microglial activation thus may be initially beneficial in $\mathrm{AD}$ pathology as show by positron emission tomography imaging studies in $\mathrm{AD}$ patients and only after becoming chronic it may exacerbate disease (Hamelin et al., 2016; Fan et al., 2017). For example, $A \beta$ direct interaction with the receptor for advance glycation end products (RAGE) increases oxidative stress in neurons, however it also enhances inflammatory response in microglia (Deane et al., 2012). By the time symptoms manifest, microglial dysfunction has already been established and it may be too late to apply current immunomodulation strategies for disease management. However, if compound administration starts as soon as the first biochemical alterations are detected, this may prove an effective preventive strategy. Therefore, a different design of clinical trials directed not towards $\mathrm{AD}$ patients, but rather people with MCI should be considered. This approach would hopefully allow to evaluate efficacy from a reduction of MCI individuals undergoing $\mathrm{AD}$ and/or a significant delay of this transition. Recent technological advances in MRI allow to discriminate healthy individuals with higher and lower brain levels of $A \beta$ accumulation (Yasuno et al., 2016) which could aid identifying patients with a higher risk of developing MCI and eventually $\mathrm{AD}$ in order to better design early intervention clinical trials. If high brain $A \beta$ levels are one of the required factors to trigger $\mathrm{AD}$, yet not the only cause, detecting abnormal $\mathrm{A} \beta$ and perhaps tau conformational changes, spreading, deposition and mislocalization at early $\mathrm{AD}$ stages may lead to define a

\section{REFERENCES}

Allfrey, V. G., Faulkner, R., and Mirsky, A. E. (1964). Acetylation and methylation of histones and their possible role in the regulation of RNA synthesis. Proc. Natl. Acad. Sci. U S A 51, 786-794. doi: 10.1073/pnas.51.5.786

An, Y. W., Jhang, K. A., Woo, S. Y., Kang, J. L., and Chong, Y. H. (2016). Sulforaphane exerts its anti-inflammatory effect against amyloid- $\beta$ peptide via STAT-1 dephosphorylation and activation of $\mathrm{Nrf} 2 / \mathrm{HO}-1$ cascade in human THP-1 macrophages. Neurobiol. Aging 38, 1-10. doi: 10.1016/j.neurobiolaging. 2015.10.016

Asadi, F., Jamshidi, A. H., Khodagholi, F., Yans, A., Azimi, L., Faizi, M., et al. (2015). Reversal effects of crocin on amyloid $\beta$-induced memory deficit: time frame in which initial beneficial microglial inflammatory responses are ongoing and immunomodulation strategies thus may prove more effective. Pharmacological therapies are currently experiencing a renaissance, thanks to multitarget drug design, in which already approved or discontinued drugs are fused with other drugs or food bioactive compounds. Thus the obtained hybrid molecule exerts multitarget directed activities derived from the original forming molecules, which may also act on different brain cell populations (Jeřábek et al., 2017). Regarding nutritional approaches, a first step could be adopting, the earlier the better, a healthy eating lifestyle, as close as possible to the Mediterranean diet, in order to increase the intake of bioactive compounds and contribute to healthy aging. Considering the multifactorial nature of cognitive impairment in aging, especially in $\mathrm{AD}$, it is evident that a multitarget-based approach is essential to address this complex condition (Bolognesi, 2013). Interestingly, this multitarget approach can be obtained through either pharmacological or nutritional strategies, however the combined use of both approaches in order to obtain a synergistic effect could be even more effective most probably as a preventive $\mathrm{AD} /$ cognitive aging strategy and perhaps also as a therapeutic approach.

\section{AUTHOR CONTRIBUTIONS}

EP-A contributed to literature search, manuscript writing, editing, revision and final approval. SP contributed to literature search and manuscript writing. FM contributed to literature search and manuscript writing. MV contributed to manuscript editing and revision. MLB contributed to manuscript editing and revision. BM contributed to manuscript editing, revision and figure preparation.

\section{FUNDING}

All authors are supported by the University of Bologna as well as a research grant from Fondazione Umberto Veronesi to EP-A.

\section{ACKNOWLEDGMENTS}

We thank Prof. Antonio Contestabile for thoroughly reading the manuscript. modification of autophagy or apoptosis markers. Pharmacol. Biochem. Behav. 139, 47-58. doi: 10.1016/j.pbb.2015.10.011

Atkinson, C., Frankenfeld, C. L., and Lampe, J. W. (2005). Gut bacterial metabolism of the soy isoflavone daidzein: exploring the relevance to human health. Exp. Biol. Med. 230, 155-170. doi: 10.1177/153537020523000302

Avital, A., Goshen, I., Kamsler, A., Segal, M., Iverfeldt, K., Richter-Levin, G., et al. (2003). Impaired interleukin-1 signaling is associated with deficits in hippocampal memory processes and neural plasticity. Hippocampus 13, 826-834. doi: 10.1002/hipo.10135

Balschun, D., Wetzel, W., Del Rey, A., Pitossi, F., Schneider, H., Zuschratter, W., et al. (2004). Interleukin-6: a cytokine to forget. FASEB J. 18, 1788-1790. doi: 10.1096/fj.04-1625fje 
Batista-de-Oliveira, M., Lopes, A. A., Mendes-da-Silva, R. F., and Guedes, R. C. (2012). Aging-dependent brain electrophysiological effects in rats after distinct lactation conditions, and treadmill exercise: a spreading depression analysis. Exp. Gerontol. 47, 452-457. doi: 10.1016/j.exger.2012.03.016

Beejmohun, V., Fliniaux, O., Grand, E., Lamblin, F., Bensaddek, L., Christen, P., et al. (2007). Microwave-assisted extraction of the main phenolic compounds in flaxseed. Phytochem. Anal. 18, 275-282. doi: 10.1002/pca.973

Bolognesi, M. L. (2013). Polypharmacology in a single drug: multitarget drugs. Curr. Med. Chem. 20, 1639-1645. doi: 10.2174/0929867311320130004

Bonet-Costa, V., Herranz-Pérez, V., Blanco-Gandía, M., Mas-Bargues, C., Inglés, M., Garcia-Tarraga, P., et al. (2016). Clearing amyloid- $\beta$ through PPAR $\gamma /$ ApoE activation by genistein is a treatment of experimental Alzheimer's disease. J. Alzheimers Dis. 51, 701-711. doi: 10.3233/JAD-151020

Braak, H., and Del Tredici, K. (2011). The pathological process underlying Alzheimer's disease in individuals under thirty. Acta Neuropathol. 121, 171-181. doi: 10.1007/s00401-010-0789-4

Brandenburg, L. O., Kipp, M., Lucius, R., Pufe, T., and Wruck, C. J. (2010). Sulforaphane suppresses LPS-induced inflammation in primary rat microglia. Inflamm. Res. 59, 443-450. doi: 10.1007/s00011-009-0116-5

Burg, V. K., Grimm, H. S., Rothhaar, T. L., Grösgen, S., Hundsdörfer, B., Haupenthal, V. J., et al. (2013). Plant sterols the better cholesterol in Alzheimer's disease? A mechanistical study. J. Neurosci. 33, 16072-16087. doi: 10.1523/JNEUROSCI.1506-13.2013

Cheng-Chung Wei, J., Huang, H. C., Chen, W. J., Huang, C. N., Peng, C. H., and Lin, C. L. (2016). Epigallocatechin gallate attenuates amyloid $\beta$-induced inflammation and neurotoxicity in EOC 13.31 microglia. Eur. J. Pharmacol. 770, 16-24. doi: 10.1016/j.ejphar.2015.11.048

Chhor, V., Le Charpentier, T., Lebon, S., Oré, M. V., Celador, I. L., Josserand, J., et al. (2013). Characterization of phenotype markers and neuronotoxic potential of polarised primary microglia in vitro. Brain Behav. Immun. 32, 70-85. doi: 10.1016/j.bbi.2013.02.005

Choi, J. Y., Kim, J. Y., Kim, J. Y., Park, J., Lee, W. T., and Lee, J. E. (2017). M2 phenotype microglia-derived cytokine stimulates proliferation and neuronal differentiation of endogenous stem cells in ischemic brain. Exp. Neurobiol. 26, 33-41. doi: 10.5607/en.2017.26.1.33

Corder, E. H., Saunders, A. M., Strittmatter, W. J., Schmechel, D. E., Gaskell, P. C., Small, G. W., et al. (1993). Gene dose of apolipoprotein E type 4 allele and the risk of Alzheimer's disease in late onset families. Science 261, 921-923. doi: $10.1126 /$ science. 8346443

Corton, J. M., Gillespie, J. G., and Hardie, D. G. (1994). Role of the AMP-activated protein kinase in the cellular stress response. Curr. Biol. 4, 315-324. doi: 10.1016/s0960-9822(00)00070-1

Csuka, E., Hans, V. H., Ammann, E., Trentz, O., Kossmann, T., and Morganti-Kossmann, M. C. (2000). Cell activation and inflammatory response following traumatic axonal injury in the rat. Neuroreport 11, 2587-2590. doi: 10.1097/00001756-200008030-00047

Cui, H., Meng, Y., and Bulleit, R. F. (1998). Inhibition of glycogen synthase kinase $3 \beta$ activity regulates proliferation of cultured cerebellar granule cells. Brain Res. Dev. Brain Res. 111, 177-188. doi: 10.1016/s0165-3806(98)00136-9

Deane, R., Singh, I., Sagare, A. P., Bell, R. D., Ross, N. T., LaRue, B., et al. (2012). A multimodal RAGE-specific inhibitor reduces amyloid $\beta$-mediated brain disorder in a mouse model of Alzheimer disease. J. Clin. Invest. 122, 1377-1392. doi: 10.1172/JCI58642

del Ser, T., Steinwachs, K. C., Gertz, H. J., Andrés, M. V., Gómez-Carrillo, B., Medina, M., et al. (2013). Treatment of Alzheimer's disease with the GSK-3 inhibitor tideglusib: a pilot study. J. Alzheimers Dis. 33, 205-215. doi: 10.3233/JAD-2012-120805

Domise, M., Didier, S., Marinangeli, C., Zhao, H., Chandakkar, P., Buée, L., et al. (2016). AMP-activated protein kinase modulates tau phosphorylation and tau pathology in vivo. Sci. Rep. 6:26758. doi: 10.1038/srep26758

Dreyer, C., Keller, H., Mahfoudi, A., Laudet, V., Krey, G., and Wahli, W. (1993). Positive regulation of the peroxisomal $\beta$-oxidation pathway by fatty acids through activation of peroxisome proliferator-activated receptors (PPAR). Biol. Cell 77, 67-74. doi: 10.1016/s0248-4900(05)80176-5

Du, L. L., Chai, D. M., Zhao, L. N., Li, X. H., Zhang, F. C., Zhang, H. B., et al. (2015). AMPK activation ameliorates Alzheimer's disease-like pathology and spatial memory impairment in a streptozotocin-induced Alzheimer's disease model in rats. J. Alzheimers Dis. 43, 775-784. doi: 10.3233/JAD-140564
Duan, H., Wearne, S. L., Rocher, A. B., Macedo, A., Morrison, J. H., and Hof, P. R. (2003). Age-related dendritic and spine changes in corticocortically projecting neurons in macaque monkeys. Cereb. Cortex 13, 950-961. doi: $10.1093 /$ cercor/13.9.950

Earnest, M. P., Heaton, R. K., Wilkinson, W. E., and Manke, W. F. (1979). Cortical atrophy, ventricular enlargement and intellectual impairment in the aged. Neurology 29, 1138-1143. doi: 10.1212/wnl.29.8.1138

Eketjäll, S., Janson, J., Jeppsson, F., Svanhagen, A., Kolmodin, K., Gustavsson, S., et al. (2013). AZ-4217: a high potency BACE inhibitor displaying acute central efficacy in different in vivo models and reduced amyloid deposition in Tg2576 mice. J. Neurosci. 33, 10075-10084. doi: 10.1523/jneurosci.116513.2013

Fan, Z., Brooks, D. J., Okello, A., and Edison, P. (2017). An early and late peak in microglial activation in Alzheimer's disease trajectory. Brain 140, 792-803. doi: 10.1093/brain/aww349

Fava, A., Colica, C., Plastino, M., Messina, D., Cristiano, D., Opipari, C., et al. (2017). Cognitive impairment is correlated with insulin resistance degree: the "PA-NICO-study". Metab. Brain Dis. 32, 799-810. doi: 10.1007/s11011-0179977-4

Ferrer, I., Barrachina, M., and Puig, B. (2002). Glycogen synthase kinase-3 is associated with neuronal and glial hyperphosphorylated tau deposits in Alzheimer's disease, Pick's disease, progressive supranuclear palsy and corticobasal degeneration. Acta Neuropathol. 104, 583-591. doi: 10.1007/s00401-002-0587-8

Giacoppo, S., Rajan, T. S., De Nicola, G. R., Iori, R., Rollin, P., Bramanti, P., et al. (2017). The isothiocyanate isolated from moringa oleifera shows potent anti-inflammatory activity in the treatment of murine subacute Parkinson's disease. Rejuvenation Res. 20, 50-63. doi: 10.1089/rej.2016.1828

Giri, S., Nath, N., Smith, B., Viollet, B., Singh, A. K., and Singh, I. (2004). 5-aminoimidazole-4-carboxamide-1- $\beta$-4-ribofuranoside inhibits proinflammatory response in glial cells: a possible role of AMP-activated protein kinase. J. Neurosci. 24, 479-487. doi: 10.1523/jneurosci.4288-03.2004

Gleason, C. E., Fischer, B. L., Dowling, N. M., Setchell, K. D., Atwood, C. S., Carlsson, C. M., et al. (2015). Cognitive effects of soy isoflavones in patients with Alzheimer's disease. J. Alzheimers Dis. 47, 1009-1019. doi: 10.3233/jad142958

Glisky, E. L. (2007). "Changes in cognitive function in human aging," in Brain Aging: Models, Methods, and Mechanisms, ed. D. R. Riddle (Boca Raton, FL: CRC Press/Taylor and Francis), Chapter 1, 3-20.

Golan, H., Levav, T., Mendelsohn, A., and Huleihel, M. (2004). Involvement of tumor necrosis factor alpha in hippocampal development and function. Cereb. Cortex 14, 97-105.

Green, H. F., and Nolan, Y. M. (2012). GSK-3 mediates the release of IL-1 $\beta$, TNF- $\alpha$ and IL-10 from cortical glia. Neurochem. Int. 61, 666-671. doi: 10.1016/j.neuint. 2012.07.003

Guerreiro, R., Wojtas, A., Bras, J., Carrasquillo, M., Rogaeva, E., Majounie, E., et al. (2013). TREM2 variants in Alzheimer's disease. N. Engl. J. Med. 368, 117-127. doi: 10.1056/NEJMoa1211851

Guo, H., Cheng, Y., Wang, C., Wu, J., Zou, Z., Niu, B., et al. (2017). FFPM, a PDE4 inhibitor, reverses learning and memory deficits in APP/PS1 transgenic mice via cAMP/PKA/CREB signaling and anti-inflammatory effects. Neuropharmacology 116, 260-269. doi: 10.1016/j.neuropharm.2017. 01.004

Guo, X. D., Sun, G. L., Zhou, T. T., Xu, X., Zhu, Z. Y., Rukachaisirikul, V., et al. (2016). Small molecule LX2343 ameliorates cognitive deficits in AD model mice by targeting both amyloid $\beta$ production and clearance. Acta Pharmacol. Sin. 37, 1281-1297. doi: 10.1038/aps.2016.80

Hailer, N. P., Jarhult, J. D., and Nitsch, R. (1996). Resting microglial cells in vitro: analysis of morphology and adhesion molecule expression in organotypic hippocampal slice cultures. Glia 18, 319-331. doi: 10.1002/(SICI)10981136(199612)18:4<319::AID-GLIA6>3.0.CO;2-S

Hamelin, L., Lagarde, J., Dorothée, G., Leroy, C., Labit, M., Comley, R. A., et al. (2016). Early and protective microglial activation in Alzheimer's disease: a prospective study using 18F-DPA-714 PET imaging. Brain 139, 1252-1264. doi: 10.1093/brain/aww017

Heringa, S. M., van den Berg, E., Reijmer, Y. D., Nijpels, G., Stehouwer, C. D., Schalkwijk, C. G., et al. (2014). Markers of low-grade inflammation and endothelial dysfunction are related to reduced information processing 
speed and executive functioning in an older population-the Hoorn Study. Psychoneuroendocrinology 40, 108-118. doi: 10.1016/j.psyneuen.2013. 11.011

Hickman, S. E., and El Khoury, J. (2014). TREM2 and the neuroimmunology of Alzheimer's disease. Biochem. Pharmacol. 88, 495-498. doi: 10.1016/j.bcp.2013. 11.021

Hidding, U., Mielke, K., Waetzig, V., Brecht, S., Hanisch, U., Behrens, A., et al. (2002). The c-Jun N-terminal kinases in cerebral microglia: immunological functions in the brain. Biochem. Pharmacol. 64, 781-788. doi: 10.1016/s00062952(02)01139-5

Hof, P. R., Duan, H., Page, T. L., Einstein, M., Wicinski, B., He, Y., et al. (2002). Age-related changes in GluR2 and NMDAR1 glutamate receptor subunit protein immunoreactivity in corticocortically projecting neurons in macaque and patas monkeys. Brain Res. 928, 175-186. doi: 10.1016/s00068993(01)03345-5

Jacobs, B., Driscoll, L., and Schall, M. (1997). Life-span dendritic and spine changes in areas 10 and 18 of human cortex: a quantitative Golgi study. J. Comp. Neurol. 386, 661-680. doi: 10.1002/(SICI)10969861(19971006)386:4<661::AID-CNE11>3.0.CO;2-N

Jacobsen, H., Ozmen, L., Caruso, A., Narquizian, R., Hilpert, H., Jacobsen, B., et al. (2014). Combined treatment with a BACE inhibitor and anti-A $\beta$ antibody gantenerumab enhances amyloid reduction in APPLondon mice. J. Neurosci. 34, 11621-11630. doi: 10.1523/jneurosci.1405-14.2014

Jeong, J. W., Lee, H. H., Han, M. H., Kim, G. Y., Kim, W. J., and Choi, Y. H. (2014). Anti-inflammatory effects of genistein via suppression of the toll-like receptor 4-mediated signaling pathway in lipopolysaccharide-stimulated BV2 microglia. Chem. Biol. Interact. 212, 30-39. doi: 10.1016/j.cbi.2014.01.012

Jeong, G. S., Li, B., Lee, D. S., Kim, K. H., Lee, I. K., Lee, K. R., et al. (2010). Cytoprotective and anti-inflammatory effects of spinasterol via the induction of heme oxygenase-1 in murine hippocampal and microglial cell lines. Int. Immunopharmacol. 10, 1587-1594. doi: 10.1016/j.intimp.2010.09.013

Jeřábek, J., Uliassi, E., Guidotti, L., Korábecný, J., Soukup, O., Sepsova, V., et al. (2017). Tacrine-resveratrol fused hybrids as multi-target-directed ligands against Alzheimer's disease. Eur. J. Med. Chem. 127, 250-262. doi: 10.1016/j.ejmech.2016.12.048

Ji, H., Wang, H., Zhang, F., Li, X., Xiang, L., and Aiguo, S. (2010). PPAR $\gamma$ agonist pioglitazone inhibits microglia inflammation by blocking p 38 mitogenactivated protein kinase signaling pathways. Inflamm. Res. 59, 921-929. doi: $10.1007 / \mathrm{s} 00011-010-0203-7$

Jonsson, T., Stefansson, H., Steinberg, S., Jonsdottir, I., Jonsson, P. V., Snaedal, J., et al. (2013). Variant of TREM2 associated with the risk of Alzheimer's disease. N. Engl. J. Med. 368, 107-116. doi: 10.1056/NEJMoa1211103

Jung, H. A., Ali, M. Y., Choi, R. J., Jeong, H. O., Chung, H. Y., and Choi, J. S. (2016). Kinetics and molecular docking studies of fucosterol and fucoxanthin, BACE1 inhibitors from brown algae Undaria pinnatifida and Ecklonia stolonifera. Food Chem. Toxicol. 89, 104-111. doi: 10.1016/j.fct.2016.01.014

Jung, H. A., Jin, S. E., Ahn, B. R., Lee, C. M., and Choi, J. S. (2013). Anti-inflammatory activity of edible brown alga Eisenia bicyclis and its constituents fucosterol and phlorotannins in LPS-stimulated RAW264.7 macrophages. Food Chem. Toxicol. 59, 199-206. doi: 10.1016/j.fct. 2013.05.061

Kamiloglu, S., Demirci, M., Selen, S., Toydemir, G., Boyacioglu, D., and Capanoglu, E. (2014). Home processing of tomatoes (Solanum lycopersicum): effects on in vitro bioaccessibility of total lycopene, phenolics, flavonoids, and antioxidant capacity. J. Sci. Food Agric. 94, 2225-2233. doi: 10.1002/ jsfa.6546

Karlinsky, H., Vaula, G., Haines, J. L., Ridgley, J., Bergeron, C., Mortilla, M., et al. (1992). Molecular and prospective phenotypic characterization of a pedigree with familial Alzheimer's disease and a missense mutation in codon 717 of the $\beta$-amyloid precursor protein gene. Neurology 42, 1445-1453. doi: 10.1212/WNL.42.8.1445

Kim, H. S., Cho, J. Y., Kim, D. H., Yan, J. J., Lee, H. K., Suh, H. W., et al. (2004). Inhibitory effects of long-term administration of ferulic acid on microglial activation induced by intracerebroventricular injection of $\beta$-amyloid peptide (1-42) in mice. Biol. Pharm. Bull. 27, 120-121. doi: 10.1248/bpb.27.120

Kim, J. H., Wang, Q., Choi, J. M., Lee, S., and Cho, E. J. (2015). Protective role of caffeic acid in an A $325-35$-induced Alzheimer's disease model. Nutr. Res. Pract. 9, 480-488. doi: 10.4162/nrp.2015.9.5.480
Kleinberger, G., Yamanishi, Y., Suárez-Calvet, M., Czirr, E., Lohmann, E., Cuyvers, E., et al. (2014). TREM2 mutations implicated in neurodegeneration impair cell surface transport and phagocytosis. Sci. Transl Med. 6:243ra86. doi: $10.1126 /$ scitranslmed.3009093

Knoops, K. T., de Groot, L. C., Kromhout, D., Perrin, A. E., Moreiras-Varela, O., Menotti, A., et al. (2004). Mediterranean diet, lifestyle factors, and 10-year mortality in elderly European men and women: the HALE project. JAMA 292, 1433-1439. doi: 10.1097/01.ieb.0000150381.96671.6b

Koriyama, Y., Sugitani, K., Ogai, K., and Kato, S. (2014). Neuritogenic activity of trichostatin $\mathrm{A}$ in adult rat retinal ganglion cells through acetylation of histone H3 lysine 9 and RAR $\beta$ induction. J. Pharmacol. Sci. 124, 112-116. doi: 10.1254/jphs.13171sc

Laeng, P., Pitts, R. L., Lemire, A. L., Drabik, C. E., Weiner, A., Tang, H., et al. (2004). The mood stabilizer valproic acid stimulates GABA neurogenesis from rat forebrain stem cells. J. Neurochem. 91, 238-251. doi: 10.1111/j.1471-4159. 2004.02725.x

Landfield, P. W., McGaugh, J. L., and Lynch, G. (1978). Impaired synaptic potentiation processes in the hippocampus of aged, memory-deficient rats. Brain Res. 150, 85-101. doi: 10.1016/0006-8993(78)90655-8

Lang, L., Dong, N., Wu, D., Yao, X., Lu, W., Zhang, C., et al. (2016). 2Arylbenzo[b]furan derivatives as potent human lipoxygenase inhibitors. J. Enzyme Inhib. Med. Chem. 31, 98-105. doi: 10.1080/147566366. 2016.1220376

Lantos, P. L., Luthert, P. J., Hanger, D., Anderton, B. H., Mullan, M., and Rossor, M. (1992). Familial Alzheimer's disease with the amyloid precursor protein position 717 mutation and sporadic Alzheimer's disease have the same cytoskeletal pathology. Neurosci. Lett. 137, 221-224. doi: 10.1016/03043940(92)90408-y

Lawson, L. J., Perry, V. H., Dri, P., and Gordon, S. (1990). Heterogeneity in the distribution and morphology of microglia in the normal adult mouse brain. Neuroscience 39, 151-170. doi: 10.1016/0306-4522(90)90229-w

Lee, H. R., Shin, H. K., Park, S. Y., Kim, H. Y., Lee, W. S., Rhim, B. Y., et al. (2014). Cilostazol suppresses $\beta$-amyloid production by activating a disintegrin and metalloproteinase 10 via the upregulation of SIRT1-coupled retinoic acid receptor- $\beta$. J. Neurosci. Res. 92, 1581-1590. doi: 10.1002/jnr.23421

Levy-Lahad, E., Wijsman, E. M., Nemens, E., Anderson, L., Goddard, K. A., Weber, J. L., et al. (1995). A familial Alzheimer's disease locus on chromosome 1. Science 269, 970-973. doi: 10.1126/science.7638621

Licht-Murava, A., Paz, R., Vaks, L., Avrahami, L., Plotkin, B., Eisenstein, M., et al. (2016). A unique type of GSK-3 inhibitor brings new opportunities to the clinic. Sci. Signal. 9:ra110. doi: 10.1126/scisignal.aah7102

Lima, C. B., Soares Gde, S., Vitor, S. M., Andrade-da-Costa, B. L., Castellano, B., and Guedes, R. C. (2014). Spreading depression features and Ibal immunoreactivity in the cerebral cortex of developing rats submitted to treadmill exercise after treatment with monosodium glutamate. Int. J. Dev. Neurosci. 33, 98-105. doi: 10.1016/j.ijdevneu.2013.12.008

Lin, H. Y., Huang, B. R., Yeh, W. L., Lee, C. H., Huang, S. S., Lai, C. H., et al. (2014). Antineuroinflammatory effects of lycopene via activation of adenosine monophosphate-activated protein kinase- $\alpha 1 /$ heme oxygenase- 1 pathways. Neurobiol. Aging 35, 191-202. doi: 10.1016/j.neurobiolaging.2013. 06.020

Liu, Z. J., Li, Z. H., Liu, L., Tang, W. X., Wang, Y., Dong, M. R., et al. (2016). Curcumin attenuates $\beta$-amyloid-induced neuroinflammation via activation of peroxisome proliferator-activated receptor- $\gamma$ function in a rat model of Alzheimer's disease. Front. Pharmacol. 7:261. doi: 10.3389/fphar.2016. 00261

Lovestone, S., Boada, M., Dubois, B., Hüll, M., Rinne, J. O., Huppertz, H. J., et al. (2015). A phase II trial of tideglusib in Alzheimer's disease. J. Alzheimers Dis. 45, 75-88. doi: 10.3233/JAD-141959

Lozano, J., Matatagui, D., Santos, J. P., and Horrillo, C. (2016). "Electronic sensory systems for characterization of bioactive compounds," in Frontiers in Bioactive Compounds (Vol. 1), ed. C. Apetrei (Sharjah: Bentham Science Publishers), 190-217.

Luccarini, I., Ed Dami, T., Grossi, C., Rigacci, S., Stefani, M., and Casamenti, F. (2014). Oleuropein aglycone counteracts $A \beta 42$ toxicity in the rat brain. Neurosci. Lett. 558, 67-72. doi: 10.1016/j.neulet.2013.10.062

Luebke, J. I., Chang, Y. M., Moore, T. L., and Rosene, D. L. (2004). Normal aging results in decreased synaptic excitation and increased synaptic inhibition of 
layer $2 / 3$ pyramidal cells in the monkey prefrontal cortex. Neuroscience 125 , 277-288. doi: 10.1016/j.neuroscience.2004.01.035

Luna-Medina, R., Cortes-Canteli, M., Sanchez-Galiano, S., Morales-Garcia, J. A., Martinez, A., Santos, A., et al. (2007). NP031112, a thiadiazolidinone compound, prevents inflammation and neurodegeneration under excitotoxic conditions: potential therapeutic role in brain disorders. J. Neurosci. 27, 5766-5776. doi: 10.1523/JNEUROSCI.1004-07.2007

Ma, T., Chen, Y., Vingtdeux, V., Zhao, H., Viollet, B., Marambaud, P., et al. (2014). Inhibition of AMP-activated protein kinase signaling alleviates impairments in hippocampal synaptic plasticity induced by amyloid $\beta$. J. Neurosci. 34, 12230-12238. doi: 10.1523/JNEUROSCI.1694-14.2014

Mashurabad, P. C., Palika, R., Jyrwa, Y. W., Bhaskarachary, K., and Pullakhandam, R. (2017). Dietary fat composition, food matrix and relative polarity modulate the micellarization and intestinal uptake of carotenoids from vegetables and fruits. J. Food Sci. Technol. 54, 333-341. doi: 10.1007/s13197016-2466-7

Matthies, A., Blaut, M., and Braune, A. (2009). Isolation of a human intestinal bacterium capable of daidzein and genistein conversion. Appl. Environ. Microbiol. 75, 1740-1744. doi: 10.1128/AEM.01795-08

Mecha, M., Feliú, A., Carrillo-Salinas, F. J., Rueda-Zubiaurre, A., OrtegaGutiérrez, S., de Sola, R. G., et al. (2015). Endocannabinoids drive the acquisition of an alternative phenotype in microglia. Brain Behav. Immun. 49, 233-245. doi: 10.1016/j.bbi.2015.06.002

Meireles, M., Marques, C., Norberto, S., Santos, P., Fernandes, I., Mateus, N., et al. (2016). Anthocyanin effects on microglia M1/M2 phenotype: consequence on neuronal fractalkine expression. Behav. Brain Res. 305, 223-228. doi: 10.1016/j. bbr.2016.03.010

Menotti, A., Kromhout, D., Nissinen, A., Giampaoli, S., Seccareccia, F., Feskens, E., et al. (1996). Short-term all-cause mortality and its determinants in elderly male populations in Finland, The Netherlands, and Italy: the FINE Study. Finland, Italy, Netherlands Elderly Study. Prev Med. 25, 319-326. doi: 10.1006/pmed. 1996.0062

Michelucci, A., Heurtaux, T., Grandbarbe, L., Morga, E., and Heuschling, P. (2009). Characterization of the microglial phenotype under specific pro-inflammatory and anti-inflammatory conditions: effects of oligomeric and fibrillar amyloid- $\beta$. J. Neuroimmunol. 210, 3-12. doi: 10.1016/j.jneuroim.2009. 02.003

Min, J. Y., and Min, K. B. (2014). Serum lycopene, lutein and zeaxanthin, and the risk of Alzheimer's disease mortality in older adults. Dement. Geriatr Cogn. Disord. 37, 246-256. doi: 10.1159/000356486

Moran, N. E., Cichon, M. J., Riedl, K. M., Grainger, E. M., Schwartz, S. J., Novotny, J. A., et al. (2015). Compartmental and noncompartmental modeling of ${ }^{13} \mathrm{C}$-lycopene absorption, isomerization, and distribution kinetics in healthy adults. Am. J. Clin. Nutr. 102, 1436-1449. doi: 10.3945/ajcn.114.103143

Mori, T., Koyama, N., Guillot-Sestier, M. V., Tan, J., and Town, T. (2013). Ferulic acid is a nutraceutical $\beta$-secretase modulator that improves behavioral impairment and alzheimer-like pathology in transgenic mice. PLoS One. 8:e55774. doi: 10.1371/journal.pone.0055774

Nam, K. N., Park, Y. M., Jung, H. J., Lee, J. Y., Min, B. D., Park, S. U., et al. (2010). Anti-inflammatory effects of crocin and crocetin in rat brain microglial cells. Eur. J. Pharmacol. 648, 110-116. doi: 10.1016/j.ejphar.2010.09.003

Neniskyte, U., Neher, J. J., and Brown, G. C. (2011). Neuronal death induced by nanomolar amyloid $\beta$ is mediated by primary phagocytosis of neurons by microglia. J. Biol. Chem. 286, 39904-39913. doi: 10.1074/jbc.M111. 267583

Nesteruk, M., Nesteruk, T., Styczyńska, M., Mandecka, M., Barczak, A., and Barcikowska, M. (2016). Combined use of biochemical and volumetric biomarkers to assess the risk of conversion of mild cognitive impairment to Alzheimer's disease. Folia Neuropathol. 54, 369-374. doi: 10.5114/fn.2016. 64815

Neumann, U., Rueeger, H., Machauer, R., Veenstra, S. J., Lueoend, R. M., Tintelnot-Blomley, M., et al. (2015). A novel BACE inhibitor NB-360 shows a superior pharmacological profile and robust reduction of amyloid$\beta$ and neuroinflammation in APP transgenic mice. Mol. Neurodegener. 10:44. doi: 10.1186/s13024-015-0033-8

Noh, M. Y., Chun, K., Kang, B. Y., Kim, H., Park, J. S., Lee, H. C., et al. (2013). Newly developed glycogen synthase kinase-3 (GSK-3) inhibitors protect neuronal cells death in amyloid- $\beta$ induced cell model and in a transgenic mouse model of Alzheimer's disease. Biochem. Biophys. Res. Commun. 435, 274-281. doi: 10.1016/j.bbrc.2013.04.065

Pangestuti, R., Vo, T. S., Ngo, D. H., and Kim, S. K. (2013). Fucoxanthin ameliorates inflammation and oxidative reponses in microglia. J. Agric. Food Chem. 61, 3876-3883. doi: 10.1021/jf400015k

Pantano, D., Luccarini, I., Nardiello, P., Servili, M., Stefani, M., and Casamenti, F. (2017). Oleuropein aglycone and polyphenols from olive mill waste water ameliorate cognitive deficits and neuropathology. Br. J. Clin. Pharmacol. 83, 54-62. doi: 10.1111/bcp.12993

Parish, C. L., Finkelstein, D. I., Tripanichkul, W., Satoskar, A. R., Drago, J., and Horne, M. K. (2002). The role of interleukin-1, interleukin-6, and glia in inducing growth of neuronal terminal arbors in mice. J. Neurosci. 22, 8034-8041.

Park, C., Lee, S., Cho, I. H., Lee, H. K., Kim, D., Choi, S. Y., et al. (2006). TLR3-mediated signal induces proinflammatory cytokine and chemokine gene expression in astrocytes: differential signaling mechanisms of TLR3-induced IP-10 and IL-8 gene expression. Glia 53, 248-256. doi: 10.1002/glia.20278

Park, S. Y., Jin, M. L., Wang, Z., Park, G., and Choi, Y. W. (2016). 2,3,4',5tetrahydroxystilbene-2-O- $\beta$-d-glucoside exerts anti-inflammatory effects on lipopolysaccharide-stimulated microglia by inhibiting NF- $\mathrm{BB}$ and activating AMPK/Nrf2 pathways. Food Chem. Toxicol. 97, 159-167. doi: 10.1016/j.fct. 2016.09.010

Pérez-Cañamás, A., Sarroca, S., Melero-Jerez, C., Porquet, D., Sansa, J., Knafo, S., et al. (2016). A diet enriched with plant sterols prevents the memory impairment induced by cholesterol loss in senescence-accelerated mice. Neurobiol. Aging 48, 1-12. doi: 10.1016/j.neurobiolaging.2016.08.009

Perez-Gonzalez, R., Pascual, C., Antequera, D., Bolos, M., Redondo, M., Perez, D. I., et al. (2013). Phosphodiesterase 7 inhibitor reduced cognitive impairment and pathological hallmarks in a mouse model of Alzheimer's disease. Neurobiol. Aging 34, 2133-2145. doi: 10.1016/j.neurobiolaging.2013. 03.011

Pohland, M., Hagl, S., Pellowska, M., Wurglics, M., Schubert-Zsilavecz, M., and Eckert, G. P. (2016). MH84: a novel $\gamma$-secretase modulator/PPAR $\gamma$ agonist-improves mitochondrial dysfunction in a cellular model of Alzheimer's disease. Neurochem. Res. 41, 231-242. doi: 10.1007/s11064015-1765-0

Polazzi, E., Altamira, L. E., Eleuteri, S., Barbaro, R., Casadio, C., Contestabile, A., et al. (2009). Neuroprotection of microglial conditioned medium on 6-hydroxydopamine-induced neuronal death: role of transforming growth factor $\beta$-2. J. Neurochem. 110, 545-556. doi: 10.1111/j.1471-4159. 2009.06117.x

Polazzi, E., Gianni, T., and Contestabile, A. (2001). Microglial cells protect cerebellar granule neurons from apoptosis: evidence for reciprocal signaling. Glia 36, 271-280. doi: 10.1002/glia.1115

Polazzi, E., Mengoni, I., Caprini, M., Peña-Altamira, E., Kurtys, E., and Monti, B. (2013). Copper-zinc superoxide dismutase (SOD1) is released by microglial cells and confers neuroprotection against 6-OHDA neurotoxicity. Neurosignals 21, 112-128. doi: 10.1159/000337115

Polazzi, E., and Monti, B. (2010). Microglia and neuroprotection: from in vitro studies to therapeutic applications. Prog. Neurobiol. 92, 293-315. doi: 10.1016/j. pneurobio.2010.06.009

Porquet, D., Casadesús, G., Bayod, S., Vicente, A., Canudas, A. M., Vilaplana, J., et al. (2013). Dietary resveratrol prevents Alzheimer's markers and increases life span in SAMP8. Age 35, 1851-1865. doi: 10.1007/s11357-012-9489-4

Prati, F., De Simone, A., Bisignano, P., Armirotti, A., Summa, M., Pizzirani, D., et al. (2015). Multitarget drug discovery for Alzheimer's disease: triazinones as BACE-1 and GSK-3 $\beta$ inhibitors. Angew. Chem. Int. Ed Engl. 54, 1578-1582. doi: 10.1002/anie.201410456

Qiao, A., Wang, Y., Zhang, W., and He, X. (2015). Neuroprotection of braintargeted bioactive dietary artoindonesianin $\mathrm{O}$ (AIO) from mulberry on rat neurons as a novel intervention for Alzheimer's disease. J. Agric. Food Chem. 63, 3687-3693. doi: 10.1021/acs.jafc.5b00396

Ransohoff, R. M., and Perry, V. H. (2009). Microglial physiology: unique stimuli, specialized responses. Annu. Rev. Immunol. 27, 119-145. doi: 10.1146/annurev. immunol.021908.132528

Rasoolijazi, H., Azad, N., Joghataei, M. T., Kerdari, M., Nikbakht, F., and Soleimani, M. (2013). The protective role of carnosic acid against $\beta$-amyloid toxicity in rats. ScientificWorldJournal 2013:917082. doi: 10.1155/2013/917082 
Reisberg, B., Ferris, S. H., de Leon, M. J., and Crook, T. (1982). The Global Deterioration Scale for assessment of primary degenerative dementia. Am. J. Psychiatry 139, 1136-1139. doi: 10.1176/ajp.139.9.1136

Ricobaraza, A., Cuadrado-Tejedor, M., and Garcia-Osta, A. (2011). Long-term phenylbutyrate administration prevents memory deficits in Tg2576 mice by decreasing A $\beta$. Front. Biosci. 3, 1375-1384. doi: 10.2741/340

Rojanathammanee, L., Puig, K. L., and Combs, C. K. (2013). Pomegranate polyphenols and extract inhibit nuclear factor of activated T-cell activity and microglial activation in vitro and in a transgenic mouse model of Alzheimer disease. J. Nutr. 143, 597-605. doi: 10.3945/jn.112.169516

Sachdeva, A. K., and Chopra, K. (2015). Lycopene abrogates A $\beta(1-42)$ mediated neuroinflammatory cascade in an experimental model of Alzheimer's disease. J. Nutr. Biochem. 26, 736-744. doi: 10.1016/j.jnutbio. 2015.01.012

Schneider, H., Pitossi, F., Balschun, D., Wagner, A., del Rey, A., and Besedovsky, H. O. (1998). A neuromodulatory role of interleukin-1 $\beta$ in the hippocampus. Proc. Natl. Acad. Sci. U S A 95, 7778-7783. doi: 10.1073/pnas. 95.13.7778

Sharma, S., and Taliyan, R. (2016). Epigenetic modifications by inhibiting histone deacetylases reverse memory impairment in insulin resistance induced cognitive deficit in mice. Neuropharmacology 105, 285-297. doi: 10.1016/j. neuropharm.2016.01.025

Sherrington, R., Rogaev, E. I., Liang, Y., Rogaeva, E. A., Levesque, G., Ikeda, M., et al. (1995). Cloning of a gene bearing missense mutations in early-onset familial Alzheimer's disease. Nature 375, 754-760. doi: 10.1038/375754a0

Shi, J. Q., Wang, B. R., Tian, Y. Y., Xu, J., Gao, L., Zhao, S. L., et al. (2013). Antiepileptics topiramate and levetiracetam alleviate behavioral deficits and reduce neuropathology in APPswe/PS1dE9 transgenic mice. CNS Neurosci. Ther. 19, 871-881. doi: 10.1111/cns.12144

Shi, X., Zheng, Z., Li, J., Xiao, Z., Qi, W., Zhang, A., et al. (2015). Curcumin inhibits $A \beta$-induced microglial inflammatory responses in vitro: involvement of ERK1/2 and p38 signaling pathways. Neurosci. Lett. 594, 105-110. doi: 10.1016/j.neulet.2015.03.045

Siebzehnrubl, F. A., Buslei, R., Eyupoglu, I. Y., Seufert, S., Hahnen, E., and Blumcke, I. (2007). Histone deacetylase inhibitors increase neuronal differentiation in adult forebrain precursor cells. Exp. Brain Res. 176, 672-678. doi: 10.1007/s00221-006-0831-x

Sierksma, A. S., van den Hove, D. L., Pfau, F., Philippens, M., Bruno, O., Fedele, E., et al. (2014). Improvement of spatial memory function in APPswe/PS1dE9 mice after chronic inhibition of phosphodiesterase type 4D. Neuropharmacology 77, 120-130. doi: 10.1016/j.neuropharm.2013. 09.015

Soiampornkul, R., Tong, L., Thangnipon, W., Balazs, R., and Cotman, C. W. (2008). Interleukin-1 $\beta$ interferes with signal transduction induced by neurotrophin-3 in cortical neurons. Brain Res. 1188, 189-197. doi: 10.1016/j. brainres.2007.10.051

Song, G. J., Nam, Y., Jo, M., Jung, M., Koo, J. Y., Cho, W., et al. (2016). A novel small-molecule agonist of PPAR- $\gamma$ potentiates an anti-inflammatory M2 glial phenotype. Neuropharmacology 109, 159-169. doi: 10.1016/j.neuropharm. 2016.06.009

Sperber, B. R., Leight, S., Goedert, M., and Lee, V. M. (1995). Glycogen synthase kinase- $3 \beta$ phosphorylates tau protein at multiple sites in intact cells. Neurosci. Lett. 197, 149-153. doi: 10.1016/0304-3940(95)11902-9

Stence, N., Waite, M., and Dailey, M. E. (2001). Dynamics of microglial activation: a confocal time-lapse analysis in hippocampal slices. Glia 33, 256-266. doi: 10.1002/1098-1136(200103)33:3<256::aid-glia1024>3.0.co;2-j

Streit, W. J. (2002). Microglia as neuroprotective, immunocompetent cells of the CNS. Glia 40, 133-139. doi: 10.1002/glia.10154

Szabo, M., and Gulya, K. (2013). Development of the microglial phenotype in culture. Neuroscience 241, 280-295. doi: 10.1016/j.neuroscience.2013. 03.033

Tai, S. Y., Chen, C. H., Chien, C. Y., and Yang, Y. H. (2017). Cilostazol as an add-on therapy for patients with Alzheimer's disease in Taiwan: a case control study. BMC Neurol. 17:40. doi: 10.1186/s12883-017-0800-y

Tarasoff-Conway, J. M., Carare, R. O., Osorio, R. S., Glodzik, L., Butler, T., Fieremans, E., et al. (2015). Clearance systems in the brain-implications for Alzheimer disease. Nat. Rev. Neurol. 11, 457-470. doi: 10.1038/nrneurol. 2015.119
Tiribuzi, R., Crispoltoni, L., Chiurchiù, V., Casella, A., Montecchiani, C., Del Pino, A. M., et al. (2017). Trans-crocetin improves amyloid- $\beta$ degradation in monocytes from Alzheimer's disease patients. J. Neurol. Sci. 372, 408-412. doi: 10.1016/j.jns.2016.11.004

Tong, M., Dominguez, C., Didsbury, J., and de la Monte, S. M. (2016). Targeting Alzheimer's disease neuro-metabolic dysfunction with a small molecule nuclear receptor agonist (T3D-959) reverses disease pathologies. J. Alzheimers Dis. Parkinsonism 6:238. doi: 10.4172/2161-0460.1000238

Tsai, C. F., Kuo, Y. H., Yeh, W. L., Wu, C. Y., Lin, H. Y., Lai, S. W., et al. (2015). Regulatory effects of caffeic acid phenethyl ester on neuroinflammation in microglial cells. Int. J. Mol. Sci. 16, 5572-5589. doi: 10.3390/ijms 16035572

Turner, R. S., Thomas, R. G., Craft, S., van Dyck, C. H., Mintzer, J., Reynolds, B. A., et al. (2015). A randomized, double-blind, placebo-controlled trial of resveratrol for Alzheimer disease. Neurology 85, 1383-1391. doi: 10.1212/WNL. 0000000000002206

Tzeng, S. -F., and Wu, J. -P. (1999). Responses of microglia and neural progenitors to mechanical brain injury. Neuroreport 10, 2287-2292. doi: 10.1097/00001756199908020-00012

Vassar, R., Bennett, B. D., Babu-Khan, S., Kahn, S., Mendiaz, E. A., Denis, P., et al. (1999). $\beta$-secretase cleavage of Alzheimer's amyloid precursor protein by the transmembrane aspartic protease BACE. Science 286, 735-741. doi: 10.1126/science.286.5440.735

Vingtdeux, V., Davies, P., Dickson, D. W., and Marambaud, P. (2011). AMPK is abnormally activated in tangle- and pre-tangle-bearing neurons in Alzheimer's disease and other tauopathies. Acta Neuropathol. 121, 337-349. doi: 10.1007/s00401-010-0759-x

Vukic, V., Callaghan, D., Walker, D., Lue, L. F., Liu, Q. Y., Couraud, P. O., et al. (2009). Expression of inflammatory genes induced by $\beta$-amyloid peptides in human brain endothelial cells and in Alzheimer's brain is mediated by the JNK-AP1 signaling pathway. Neurobiol. Dis. 34, 95-106. doi: 10.1016/j.nbd. 2008.12.007

Waetzig, V., Czeloth, K., Hidding, U., Mielke, K., Kanzow, M., Brecht, S., et al. (2005). c-Jun N-terminal kinases (JNKs) mediate pro-inflammatory actions of microglia. Glia 50, 235-246. doi: 10.1002/glia.20173

Wang, G., Chen, L., Pan, X., Chen, J., Wang, L., Wang, W., et al. (2016). The effect of resveratrol on $\beta$ amyloid-induced memory impairment involves inhibition of phosphodiesterase-4 related signaling. Oncotarget 7 , 17380-17392. doi: 10.18632/oncotarget.8041

Wang, D., Ho, L., Faith, J., Ono, K., Janle, E. M., Lachcik, P. J., et al. (2015). Role of intestinal microbiota in the generation of polyphenol-derived phenolic acid mediated attenuation of Alzheimer's disease $\beta$-amyloid oligomerization. Mol. Nutr. Food Res. 59, 1025-1040. doi: 10.1002/mnfr.201400544

Winblad, B., Palmer, K., Kivipelto, M., Jelic, V., Fratiglioni, L., Wahlund, L. O., et al. (2004). Mild cognitive impairment-beyond controversies, towards a consensus: report of the international working group on mild cognitive impairment. J. Intern. Med. 256, 240-246. doi: 10.1111/j.1365-2796.2004. 01380.x

Wu, W., Li, Y., Wu, Y., Zhang, Y., Wang, Z., and Liu, X. (2015). Lutein suppresses inflammatory responses through Nrf2 activation and NF-кB inactivation in lipopolysaccharide-stimulated BV-2 microglia. Mol. Nutr. Food Res. 59, 1663-1673. doi: 10.1002/mnfr.201500109

Xu, P. X., Wang, S. W., Yu, X. L., Su, Y. J., Wang, T., Zhou, W. W., et al. (2014). Rutin improves spatial memory in Alzheimer's disease transgenic mice by reducing $A \beta$ oligomer level and attenuating oxidative stress and neuroinflammation. Behav. Brain Res. 264, 173-180. doi: 10.1016/j.bbr.2014. 02.002

Xu, Y., Xu, Y., Wang, Y., Wang, Y., He, L., Jiang, Z., et al. (2015). Telmisartan prevention of LPS-induced microglia activation involves M2 microglia polarization via CaMKK $\beta$-dependent AMPK activation. Brain Behav. Immun. 50, 298-313. doi: 10.1016/j.bbi.2015.07.015

Xu, G., Zhou, Z., Zhu, W., Fan, X., and Liu, X. (2009). Plasma C-reactive protein is related to cognitive deterioration and dementia in patients with mild cognitive impairment. J. Neurol. Sci. 284, 77-80. doi: 10.1016/j.jns. 2009.04.018

Yamakawa, M. Y., Uchino, K., Watanabe, Y., Adachi, T., Nakanishi, M., Ichino, H., et al. (2016). Anthocyanin suppresses the toxicity of A $\beta$ deposits through diversion of molecular forms in in vitro and in vivo models of Alzheimer's disease. Nutr. Neurosci. 19, 32-42. doi: 10.1179/1476830515Y.0000000042 
Yanagitai, M., Itoh, S., Kitagawa, T., Takenouchi, T., Kitani, H., and Satoh, T. (2012). Carnosic acid, a pro-electrophilic compound, inhibits LPS-induced activation of microglia. Biochem. Biophys. Res. Commun. 418, 22-26. doi: 10.1016/j.bbrc.2011.12.087

Yao, Y., Li, J., Niu, Y., Yu, J. Q., Yan, L., Miao, Z. H., et al. (2015). Resveratrol inhibits oligomeric A $\beta$-nduced microglial activation via NADPH oxidase. Mol. Med. Rep. 12, 6133-6139. doi: 10.3892/mmr.2015.4199

Yasuno, F., Kazui, H., Morita, N., Kajimoto, K., Ihara, M., and Taguchi, A. (2016). Use of T1-weighted/T2-weighted magnetic resonance ratio to elucidate changes due to amyloid $\beta$ accumulation in cognitively normal subjects. Neuroimage Clin. 13, 209-214. doi: 10.1016/j.nicl.2016.11.029

Ye, S. M., and Johnson, R. W. (1999). Increased interleukin-6 expression by microglia from brain of aged mice. J. Neuroimmunol. 93, 139-148. doi: 10.1016/s0165-5728(98)00217-3

Ye, S. M., and Johnson, R. W. (2001). An age-related decline in interleukin-10 may contribute to the increased expression of interleukin- 6 in brain of aged mice. Neuroimmunomodulation 9, 183-192. doi: 10.1159/000049025

Zhang, J., Guo, J., Zhao, X., Chen, Z., Wang, G., Liu, A., et al. (2013). Phosphodiesterase-5 inhibitor sildenafil prevents neuroinflammation, lowers $\beta$-amyloid levels and improves cognitive performance in APP/PS1 transgenic mice. Behav. Brain Res. 250, 230-237. doi: 10.1016/j.bbr. 2013.05.017

Zhang, R., Miao, Q. W., Zhu, C. X., Zhao, Y., Liu, L., Yang, J., et al. (2015). Sulforaphane ameliorates neurobehavioral deficits and protects the brain from amyloid $\beta$ deposits and peroxidation in mice with Alzheimer-like lesions. Am. J. Alzheimers Dis. Other Demen. 30, 183-191. doi: 10.1177/1533317514542645

Zhang, Z. Y., and Schluesener, H. J. (2013). Oral administration of histone deacetylase inhibitor MS-275 ameliorates neuroinflammation and cerebral amyloidosis and improves behavior in a mouse model. J. Neuropathol. Exp. Neurol. 72, 178-185. doi: 10.1097/NEN.0b013e318283114a

Zhang, Z., Wu, H., and Huang, H. (2016). Epicatechin plus treadmill exercise are neuroprotective against moderate-stage amyloid precursor protein/ presenilin 1 mice. Pharmacogn. Mag. 12, S139-S146. doi: 10.4103/0973-1296. 182174

Zhao, H., Cheng, L., Liu, Y., Zhang, W., Maharjan, S., Cui, Z., et al. (2014). Mechanisms of anti-inflammatory property of conserved dopamine neurotrophic factor: inhibition of JNK signaling in lipopolysaccharide-induced microglia. J. Mol. Neurosci. 52, 186-192. doi: 10.1007/s12031-013-0120-7

Zhao, D., Kwon, S. H., Chun, Y. S., Gu, M. Y., and Yang, H. O. (2017). Anti-neuroinflammatory effects of fucoxanthin via inhibition of Akt/NF- $\mathrm{B}$ and MAPKs/AP-1 pathways and activation of PKA/CREB pathway in lipopolysaccharide-activated BV-2 microglial cells. Neurochem. Res. 42, 667-677. doi: 10.1007/s11064-016-2123-6

Zhou, Q., Wang, M., Du, Y., Zhang, W., Bai, M., Zhang, Z., et al. (2015). Inhibition of c-Jun $\mathrm{N}$-terminal kinase activation reverses Alzheimer disease phenotypes in APPswe/PS1dE9 mice. Ann. Neurol. 77, 637-654. doi: 10.1002/ana. 24361

Zhu, X., Raina, A. K., Rottkamp, C. A., Aliev, G., Perry, G., Boux, H., et al. (2001). Activation and redistribution of c-jun $\mathrm{N}$-terminal kinase/stress activated protein kinase in degenerating neurons in Alzheimer's disease. J. Neurochem. 76, 435-441. doi: 10.1046/j.1471-4159.2001.00046.x

Zhu, L., Yang, J. Y., Xue, X., Dong, Y. X., Liu, Y., Miao, F. R., et al. (2015). A novel phosphodiesterase-5 Inhibitor: yonkenafil modulates neurogenesis, gliosis to improve cognitive function and ameliorates amyloid burden in an APP/PS1 transgenic mice model. Mech. Ageing Dev. 150, 34-45. doi: 10.1016/j. mad.2015.07.002

Zong, H., Ren, J. M., Young, L. H., Pypaert, M., Mu, J., Birnbaum, M. J., et al. (2002). AMP kinase is required for mitochondrial biogenesis in skeletal muscle in response to chronic energy deprivation. Proc. Natl. Acad. Sci. U S A 99, 15983-15987. doi: 10.1073/pnas.252625599

Conflict of Interest Statement: The authors declare that the research was conducted in the absence of any commercial or financial relationships that could be construed as a potential conflict of interest.

Copyright (๑) 2017 Peña-Altamira, Petralla, Massenzio, Virgili, Bolognesi and Monti. This is an open-access article distributed under the terms of the Creative Commons Attribution License (CC BY). The use, distribution or reproduction in other forums is permitted, provided the original author(s) or licensor are credited and that the original publication in this journal is cited, in accordance with accepted academic practice. No use, distribution or reproduction is permitted which does not comply with these terms. 